\title{
MICU1 regulates mitochondrial cristae structure and function independent of the mitochondrial calcium uniporter channel
}

Dhanendra Tomar ${ }^{1}$, Manfred Thomas ${ }^{1}$, Joanne F. Garbincius ${ }^{1}$, Devin W. Kolmetzky ${ }^{1}$, Oniel Salik $^{1,2}$, Pooja Jadiya ${ }^{1}$, April C. Carpenter ${ }^{2}$, John W. Elrod ${ }^{1 *}$

${ }^{1}$ Center for Translational Medicine, Department of Pharmacology, Lewis Katz School of Medicine at Temple University, Philadelphia, PA 19140

${ }^{2}$ Ursinus College, Collegeville, PA 19426, USA

\section{${ }^{*}$ Correspondence:}

John W. Elrod, PhD

Center for Translational Medicine

3500 N Broad St, MERB 949

Philadelphia, PA 19140

Office: (215) 707-5480

LAB: (215) 707-9144

Fax: (215) 707-9890

elrod@temple.edu

elrodlab.org

Conflict of interest: The authors have no financial conflict of interest to report.

Keywords: mitochondria; calcium regulation; calcium signaling; MICU1; cristae junctions; MICOS; MIC60; CHCHD2; MCU; mtCU; 


\section{Abstract}

2 MICU1 is an EF-hand-containing mitochondrial protein that is essential for gating of the

3 mitochondrial $\mathrm{Ca}^{2+}$ uniporter channel ( $\mathrm{mtCU}$ ) and is reported to interact directly with the pore-

4 forming subunit, MCU and scaffold EMRE. However, using size-exclusion proteomics, we found

5 that MICU1 exists in mitochondrial complexes lacking MCU. This suggests that MICU1 may

6 have additional cellular functions independent of regulating mitochondrial $\mathrm{Ca}^{2+}$ uptake. To

7 discern mtCU-independent MICU1 functions, we employed a proteomic discovery approach

8 using BiolD2-mediated proximity-based $(<10 \mathrm{~nm})$ biotinylation and subsequent LC-MS detection.

9 The expression of a MICU1-BiolD2 fusion protein in $\mathrm{MICU}^{-\%}$ and $\mathrm{MCU}^{-}$cells allowed the identification of total vs. mtCU-independent MICU1 interactors. Bioinformatics identified the

11 Mitochondrial Contact Site and Cristae Organizing System (MICOS) components MIC60

12 (encoded by the IMMT gene) and Coiled-coil-helix-coiled-coil helix domain containing 2

13 (CHCHD2) as novel MICU1 interactors, independent of the mtCU. We demonstrate that MICU1

14 is essential for proper proteomic organization of the MICOS complex and that MICU1 ablation

15 results in altered cristae organization and mitochondrial ultrastructure. We hypothesize that

16 MICU1 serves as a MICOS calcium sensor, since perturbing MICU1 is sufficient to modulate

17 cytochrome $\mathrm{c}$ release independent of mitochondrial $\mathrm{Ca}^{2+}$ uptake across the inner mitochondrial

18 membrane (IMM). Here, we provide the first experimental evidence suggesting that MICU1

19 regulates cellular functions independent of mitochondrial calcium uptake and may serve as a

20 critical mediator of $\mathrm{Ca}^{2+}$-dependent signaling to modulate mitochondrial membrane dynamics

21 and cristae organization. 


\section{Introduction}

Calcium $\left(\mathrm{Ca}^{2+}\right)$ is well characterized as an essential second messenger that regulates numerous cellular functions by binding distinct $\mathrm{Ca}^{2+}$ sensing domains or motifs present on numerous proteins (Bagur and Hajnoczky, 2017; Carafoli, 2002, 2003). Most Ca ${ }^{2+}$ sensors contain more than one $\mathrm{Ca}^{2+}$ binding domain, often with varied affinities for $\mathrm{Ca}^{2+}$ binding, resulting in diverse and graded functions in a variety of cellular processes (Bagur and Hajnoczky, 2017; Carafoli, 2002, 2003; Tadross et al., 2008). The $\mathrm{Ca}^{2+}$ concentration varies greatly between different cellular compartments, and thus $\mathrm{Ca}^{2+}$ sensors are strategically localized for subcellular/organelle specific signaling (Bagur and Hajnoczky, 2017; Rizzuto et al., 2012; Rizzuto and Pozzan, 2006). Mitochondria actively regulate their $\mathrm{Ca}^{2+}$ concentration and contain $\mathrm{Ca}^{2+}$ sensors to mediate anterograde and retrograde signaling (Bagur and Hajnoczky, 2017; Rizzuto et al., 2012). Examples include Mitochondrial Rho GTPases (MIROs) localized to the outer mitochondrial membrane (OMM), and Mitochondrial calcium uptake proteins (MICUs) localized to the inter-membrane space (IMS) side of the IMM (Bagur and Hajnoczky, 2017; Fransson et al., 2003; Perocchi et al., 2010; Plovanich et al., 2013). MIRO Ca ${ }^{2+}$ sensing is essential for mitochondrial trafficking and structural homeostasis (Bagur and Hajnoczky, 2017; Fransson et al., 2003; Frederick et al., 2004; Nemani et al., 2018; Saotome et al., 2008), while MICUs are known to gate the mitochondrial calcium uniporter channel (mtCU) and regulate its open probability (Csordas et al., 2013; Liu et al., 2016; Mallilankaraman et al., 2012b; Patron et al., 2014; Plovanich et al., 2013).

The mtCU is a highly selective $\mathrm{Ca}^{2+}$ channel necessary for acute $\mathrm{Ca}^{2+}$ entry to the mitochondrial matrix (Baughman et al., 2011; De Stefani et al., 2011; Kirichok et al., 2004; Rizzuto et al., 2012). The mtCU consists of multiple subunits, namely the pore-forming component Mitochondrial Calcium Uniporter (MCU) and its homolog, MCUB; the regulatory scaffolds MCU Regulator 1 (MCUR1) and Essential MCU Regulator Element (EMRE); and the $\mathrm{Ca}^{2+}$ sensors 
47 Mitochondrial Calcium Uptake proteins 1, 2, and 3 (MICU1, MICU2 and MICU3) (Baughman et

48 al., 2011; De Stefani et al., 2011; Mallilankaraman et al., 2012a; Perocchi et al., 2010; Plovanich

49 et al., 2013; Raffaello et al., 2013; Sancak et al., 2013; Tomar et al., 2016). MICU1 is essential

50 to $\mathrm{mtCU}$ regulation, by directly binding MCU and EMRE and its expression correlates with

51 tissue-dependent differences in mitochondrial calcium uptake (Csordas et al., 2013;

52 Mallilankaraman et al., 2012b; Paillard et al., 2018; Patron et al., 2014; Perocchi et al., 2010;

53 Phillips et al., 2019; Plovanich et al., 2013; Sancak et al., 2013; Xing et al., 2019).

54 Loss-of-function mutations in MICU1 induce proximal myopathy, learning difficulties, movement

55 disorder, fatigue, and lethargy in humans (Lewis-Smith et al., 2016; Logan et al., 2014) and

56 deletion of Micu1 in mouse models causes perinatal lethality (Antony et al., 2016; Liu et al.,

57 2016). Recently, genetic mutants were generated to characterize mtCU regulation in Drosophila

58 (Tufi et al., 2019). Intriguingly, Tufi et al. reported that a MICU1 loss-of-function mutation

59 resulted in Drosophila lethality, which could not be rescued by a concurrent MCU loss-of-

60 function mutation that completely ablated mitochondrial $\mathrm{Ca}^{2+}\left({ }_{\mathrm{m}} \mathrm{Ca}^{2+}\right)$ uptake and subsequent

61 mitochondrial permeability transition pore opening (Tufi et al., 2019). This observation suggests

62 that the lethal phenotype of MICU1-null flies was not solely a result of aberrant mtCU-dependent

$63 \mathrm{Ca}^{2+}$ uptake. This raises the possibility that MICU1 has mtCU-independent functions, which are

64 vital for mitochondrial function and survival. Indeed, MICU1 knockout models show distinct

65 abnormalities in mitochondrial ultrastructure that are not observed in any other mtCU knockout

66 models (Bick et al., 2017; Liu et al., 2016; Luongo et al., 2015; Tomar et al., 2016). Additionally,

67 MICU1 protein is reported to have high mobility within the IMM as compared to the MCU

68 (Hoffman et al., 2013), suggesting that MICU1 could be associated with other complexes in the

69 mitochondria. These observations led us to hypothesize that MICU1 regulates other essential

70 mitochondrial processes beyond calcium uptake. 
71 To discover mtCU-independent functions of the MICU1, we utilized a proximity-based

72 biotinylation approach by generating a MICU1-BioID2 fusion protein. BiolD2 is a recently

73 developed, highly-efficient promiscuous biotin ligase which enables the detection of protein-

74 protein interactions in living cells (Kim et al., 2016). We reconstituted MICU1 ${ }^{-/-}$cells with MICU1-

75 BiolD2-HA to avoid aberrant localization associated with overexpression to characterize the

76 entire MICU1 interactome. We also expressed MICU1-BiolD2-HA in $M C U^{\prime-}$ cells to define

77 mtCU-independent interactions. Through a comparative analysis of mass-spectrometry, we

78 identified proteins whose interaction with MICU1 was unaffected by the loss of MCU. Here, we

79 report that MICU1 directly interacts with the Mitochondrial Contact Site and Cristae Organizing

80 System (MICOS) components MIC60, and CHCHD2 in an MCU-independent manner. Our

81 results suggest that MICU1 confers calcium sensing to the MICOS for cell signaling-dependent

82 changes in cristae structure and function.

\section{Results and Discussion}

\section{Observation of MICU1 localization independent of the mtCU}

85 To define the mtCU-independent molecular functions of the MICU1, we first utilized size exclusion chromatography to characterize the native organization of MICU1-containing protein complexes. Total cell lysates prepared from HEK293T $\mathrm{MCU}^{+/+}$and $\mathrm{MCU}^{{ }^{-}}$cells were fractioned in non-reducing conditions by Fast Protein Liquid Chromatography (FPLC). FPLC fractions ranging from $\sim 10 \mathrm{kDa}$ to $\sim 900 \mathrm{kDa}$ were collected, concentrated and examined for the MICU1 protein complexes using reducing SDS-PAGE and Western blotting (Figure 1A, 1B). MICU1

91 forms distinct high-molecular weight (MW) protein complexes ranging from $\sim 200 \mathrm{kDa}$ to $\sim 700$

$92 \mathrm{kDa}$ (Figure 1A, 1B). Intriguingly, the loss of MCU does not have a substantial effect on the 93 overall distribution of MICU1-containing high-molecular weight (MW) protein complexes (Figure

94 1A, 1B). Next, we examined mitochondrial sub-localization of MCU and MICU1 by

95 immunofluorescent detection of native MCU and FLAG-tagged MICU1 in Micu ${ }^{-/-}$mouse 
embryonic fibroblasts (MEFs) to enable accurate detection of MICU1 and avoid aberrant

97 localization associated with overexpression (Figure 1C). The deletion of MICU1 in MEFs was confirmed by Western blotting (Figure S1A). Line-scan analysis of the mitochondrial network clearly shows that MICU1 co-localizes with MCU, but also distributes to sub-mitochondrial regions lacking MCU (Figure 1C,1D). These results suggest that MICU1 is present in mitochondrial protein complexes where the $\mathrm{mtCU}$ is absent.

Next, we characterized the mtCU-independent interactome of MICU1. We generated a MICU1BiolD2-HA fusion protein to enable the biotinylation of interactors $(<10 \mathrm{~nm})$ in $\mathrm{MCU}^{+/+}$and $\mathrm{MCU}^{/-}$ cells to distinguish the mtCU-dependent vs. -independent MICU1 interactomes (Figure 1E). Expression, biotin ligase activity, sub-mitochondrial localization and reconstitution of $\mathrm{Ca}^{2+}$ uptake regulation of MICU1-BioID2-HA fusion protein was confirmed in $\mathrm{MICU} 1^{-}$cells expressing the MICU1-BiolD2-HA fusion protein (Figure 1F, 1G, S1B). These data show that our fusion construct was properly localized and that mtCU-dependent calcium uptake was not altered in our discovery system. Next, we expressed the MICU1-BiolD2 or BiolD2 control in HEK293T $\mathrm{MICU}^{-/}$cells (hereafter $\mathrm{MCU}^{+/+}$) and HEK293T $\mathrm{MCU}^{-/}$cells (hereafter $\mathrm{MCU}^{\prime-}$ )

(Figure $1 \mathrm{H}$ ). Biotinylation of proteins proximal to MICU1-BiolD2 was induced by culturing cells in 112 presence of biotin $(50 \mu \mathrm{M})$ for $16 \mathrm{~h}$ (Figure 1H). MICU1-BiolD2-HA protein expression and biotin 113 ligase activity were confirmed via Western blotting (Figure $1 \mathrm{H}$ ). Next, biotinylated proteins were 114 purified from cell lysates using streptavidin-conjugated magnetic beads. Peptides were

115 generated from the purified biotinylated proteins by tryptic digestion, and LC-MS was performed 116 (Kim et al., 2016). Comparative analysis of MICU1 proximal proteins identified in $\mathrm{MCU}^{+/+}$vs.

$117 \mathrm{MCU}^{/-}$cells was performed (Figure 1I). The MICOS components MIC60, CHCHD3, CHCHD2, 118 APOO, and APOOL emerged as 'hits' from a single multiprotein complex present at the inner 119 mitochondrial membrane (IMM), and proximity to MICU1 was unaltered in $\mathrm{MCU}^{/-}$cells (Figure 120 1I, Table S1). 


\section{MICU1 directly interacts with MIC60 and CHCHD2 in the MICOS complex}

122 The three core MICOS components along with OPA1, which is also involved in cristae

123 organization, emerged as MICU1 proximal proteins in our proteomic screen (Figure 1I, Table

124 S1). However, the loss of MCU results in loss of the MICU1:OPA1 interaction, while the MICU1

125 interaction with the core MICOS components is preserved (Figure 1I, Table S1). This observation suggests that MICU1 could be an integral component of the MICOS complex and

127 involved in mitochondrial cristae organization, independent of the mtCU and mitochondrial calcium uptake. To assess if MICU1 directly binds MIC60, CHCHD2, and CHCHD3 we coexpressed MIC60-FLAG, CHCHD2-FLAG, or CHCHD3-FLAG with MICU1-HA and 48h posttransfection, we performed immunoprecipitation (IP) with FLAG-conjugated magnetic beads.

131 IP'd products were analyzed by SDS-PAGE and Western blotting for HA immunoreactivity, to 132 detect MICU1, and FLAG expression, to detect MICOS components (Figure 2A). To control for 133 level of expression we blotted for FLAG-tagged MIC60 ( 90kDa), CHCHD2 ( 16kDa), and $134 \mathrm{CHCHD} 3(\sim 26 \mathrm{kDa})$ and HA-tagged MICU1 ( 55kDa) (Figure 2A). All were expressed to similar 135 degrees, but only MIC60 and CHCHD2 pulled-down with MICU1 (Figure 2A). We validated this 136 result by reverse IPs and confirmed the interaction of MICU1-FLAG with endogenous MIC60 137 and $\mathrm{CHCHD} 2$, but not with $\mathrm{CHCHD} 3$ (Figure S2A). This suggests that MICU1 may directly 138 interact with MIC60 and $\mathrm{CHCHD} 2$, but not with $\mathrm{CHCHD} 3$ and that its biotinylation in our 139 discovery assay was likely due to its general proximity to MICU1. To substantiate the MICU1 140 interaction with MIC60 and $\mathrm{CHCHD} 2$ we performed co-immunofluorescence labeling and 141 imaged to examine sub-mitochondrial localization (Figure 2B, 2C, 2D, 2E). The line-scan profile 142 shows distinct pixels with spectral overlap of MICU1 with MIC60, and MICU1 with CHCHD2

143 (Figure 2C, 2E). Together, these data suggest that MICU1 directly interacts with the core MICOS components. 
145 To further characterize the functional relevance of MICU1 interaction with MICOS components,

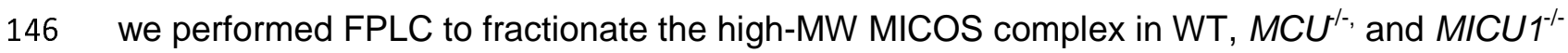

147 cells. Immunoblots of 19 fractions ranging from $\sim 10 \mathrm{kDa}$ to $\sim 900 \mathrm{kDa}$ were probed for MIC60,

$148 \mathrm{CHCHD} 2$ and $\mathrm{CHCHD} 3$ expression; all showed robust immunoreactivity in native protein

149 complexes ranging from $\sim 400-700 \mathrm{kD}$ (Figure 2F- 2I, S2B, S2C). Interestingly, genetic deletion

150 of $M C U$ had no effect on the overall size or fraction distribution of the multi-subunit MICOS

151 complex (Figure 2F-2I, S2B, S2C). However, the loss of MICU1 expression resulted in a

152 rightward shift, decrease in overall $\mathrm{MW}$, of $\mathrm{MIC60}, \mathrm{CHCHD} 2$, and $\mathrm{CHCHD} 3$ containing

153 complexes (Figure 2F- 2I, S2B, S2C) suggesting that MICU1 may play an integral role in

154 MICOS complex assembly or stability.

MICU1 is essential for the maintenance of mitochondrial ultrastructure and cristae

157 The MICOS is essential for maintenance of mitochondrial membrane topology and bottleneck 158 formation (Friedman et al., 2015; Harner et al., 2011; Tarasenko et al., 2017; van der Laan et 159 al., 2016). The MICOS is localized at the intersection of the IMM and OMM, which results in the 160 formation of membrane contact sites at cristae junctions (Friedman et al., 2015; Harner et al., 2011; Tarasenko et al., 2017; van der Laan et al., 2016). $\mathrm{Ca}^{2+}$ is reported to modulate the cristae structure (Gottschalk et al., 2018; Greenawalt et al., 1964), however, no $\mathrm{Ca}^{2+}$-sensing protein has yet been identified as an essential component of the MICOS. To discern if MICU1 serves as a conduit for calcium-dependent regulation of the MICOS, we examined if genetic loss of MICU1 had any effect on mitochondrial ultrastructure and cristae junctions. In agreement with previous reports, transmission electron microscopy (TEM) revealed gross changes in

167 mitochondrial ultrastructure of cells lacking MICU1 (Figure 3A- 3D). Careful quantitative analysis 
170

171

172

173

174

175

176

177

178

179

180

181

182

183

184

185

186

187

188

189

190

191

192

193

ratio are significantly reduced in $M I C U 1^{-/-}$cells (Figure 3B-3D). This suggests that mitochondria are less filamentous in $\mathrm{MICU} 1^{-/-}$cells. Next, we analyzed the inter-cristae junction (distance between cristae) and the cristae junction width (distance between IMM of the same cristae) in WT and $\mathrm{MICU}^{-1_{-}^{-}}$cells. The inter-cristae junction distance is reported to be directly proportional to cristae density. MICU $1^{-/-}$cells displayed a significant increase in both the inter-cristae junction distance and cristae junction width, as compared to WT cells (Figure 3E, 3F).

The bottleneck structure of cristae is essential to the maintenance of the mitochondrial respiratory chain complexes (Friedman et al., 2015; van der Laan et al., 2016). Disorganization and cristae remodeling is associated with the release of cytochrome c from bottlenecks, which subsequently induces cell death signaling pathways (Scorrano et al., 2002). To further define the role of MICU1 in cristae regulation, we monitored tBid-induced cytochrome c release in primary $\mathrm{Micu}^{-1-}$ mouse embryonic fibroblasts (MEFs). The loss of MICU1 resulted in increased basal cytochrome c release and this was potentiated after tBID treatment (Figure 3G, 3H). To rule out possible indirect effects of MICU1 regulation of $\mathrm{mtCU}-\mathrm{Ca}^{2+}$ uptake on cristae structure, we examined ${ }_{\mathrm{m}} \mathrm{Ca}^{2+}$ uptake in $C h c h d 2^{--}$MEFs. CHCHD2 was previously identified as a core MICOS component and its genetic deletion results in abnormal cristae organization (Meng et al., 2017). WT and Chchd2/- MEFs were permeabilized with digitonin in the presence of thapsigargin to monitor ${ }_{\mathrm{m}} \mathrm{Ca}^{2+}$ uptake independent of plasma membrane and $\mathrm{ER}^{\mathrm{Ca}^{2+}}$ transport using ratiometric $\mathrm{Ca}^{2+}$ sensor. Chchd2/- cells showed no change in ${ }_{\mathrm{m}} \mathrm{Ca}^{2+}$ uptake suggesting that altered cristae structure alone is insufficient to impact mtCU-dependent ${ }_{\mathrm{m}} \mathrm{Ca}^{2+}$ uptake (Figure S3A, S3B). Further, we found that loss of $\mathrm{CHCHD} 2$ had no effect on mitochondrial calcium efflux (rate of $\mathrm{Ca}^{2+}$ exiting the matrix after Ru360 blockade of MCU; Figure S3A, S3C). We also examined the high-MW/functional mtCU complex in Chchd2 ${ }^{/-}$MEFs by FPLC-based protein fractionation and observed no change in MCU distribution (Figure S3D, S3E). These 
194 observations suggest that altered cristae structure alone does not have a significant impact on

195 mtCU assembly or ${ }_{m} \mathrm{Ca}^{2+}$ dynamics.

196 In summary, we characterized the MICU1 interactome and identified a distinct involvement in

197 cristae organization independent of the mtCU and mitochondrial calcium uptake. Our study

198 reveals a direct interaction between MICU1 and core MICOS components and shows that this

199 interaction is essential to form the functional MICOS complex. This mechanism could explain

200 the lethal phenotype observed in MICU1 knockout models (Antony et al., 2016; Liu et al., 2016;

201 Tufi et al., 2019), as our results suggest that loss of MICU1 could induce both necrotic, as well

202 as apoptotic, death signaling events independent of matrix $\mathrm{Ca}^{2+}$ overload. Our results also

203 highlight the need to reappraise the MICU1/mtCU literature as some of the reported phenotypes

204 may be influenced by alterations in the function/structure of the MICOS, rather than dependent

205 on changes in mitochondrial calcium uptake. Further research is needed to define the precise

206 interaction of MICU1 with MICOS components to hopefully identify tools to enable the dissection

207 of mtCU-dependent vs. independent functions in mitochondrial biology. In summary, the current

208 study identified a novel role for MICU1 in regulating the cristae junction, independent of the

$209 \mathrm{mtCU}$, which is essential for mitochondrial physiology. 


\section{Key resources table}

\begin{tabular}{|c|c|c|c|c|}
\hline $\begin{array}{l}\text { Reagent } \\
\text { type or } \\
\text { resource }\end{array}$ & Designation & Source or reference & Identifiers & $\begin{array}{l}\text { Additional } \\
\text { information }\end{array}$ \\
\hline \multirow[t]{7}{*}{ Cell lines } & HEK293T WT & (Sancak et al., 2013) & & \\
\hline & HEK293T $M C U^{\prime-}$ & (Sancak et al., 2013) & & \\
\hline & HEK293T MICU1 ${ }^{-1-}$ & (Sancak et al., 2013) & & \\
\hline & MEF Micu1 $1^{+/+}$ & This study & & \\
\hline & MEF Micu1 ${ }^{-1-}$ & This study & & \\
\hline & MEF Chchd2 ${ }^{+/+}$ & (Meng et al., 2017) & & \\
\hline & MEF Chchd2/-- & (Meng et al., 2017) & & \\
\hline \multirow[t]{10}{*}{ Plasmids } & MCS-BiolD2-HA & Addgene (Kim et al., 2016) & Cat\# 74224 & \\
\hline & Start-BiolD2-HA & This study & & \\
\hline & MICU1-BiolD2-HA & This study & & \\
\hline & hMICU1-Myc-DDK & OriGene Technologies & Cat\# RC200921 & \\
\hline & MICU1-FLAG & OriGene Technologies & Cat\# MR207652 & \\
\hline & pCMV6-AC-HA & OriGene Technologies & Cat\# PS100004 & \\
\hline & MICU1-HA & This study & & \\
\hline & MIC60-FLAG & OriGene Technologies & Cat\# MR216091 & \\
\hline & CHCHD3-FLAG & OriGene Technologies & Cat\# MR202692 & \\
\hline & CHCHD2-FLAG & OriGene Technologies & Cat\# MR223513 & \\
\hline Antibodies & $\begin{array}{l}\text { Anti-MIC60 } \\
\text { IMMT Rabbit } \\
\text { Polyclonal Antibody } \\
(10179-1-A P)\end{array}$ & Proteintech & $\begin{array}{l}\text { Cat\# 10179-1- } \\
\text { AP }\end{array}$ & $\begin{array}{l}\text { WB 1:1000 } \\
\text { IF 1:200 } \\
\text { PLA 1:200 }\end{array}$ \\
\hline
\end{tabular}




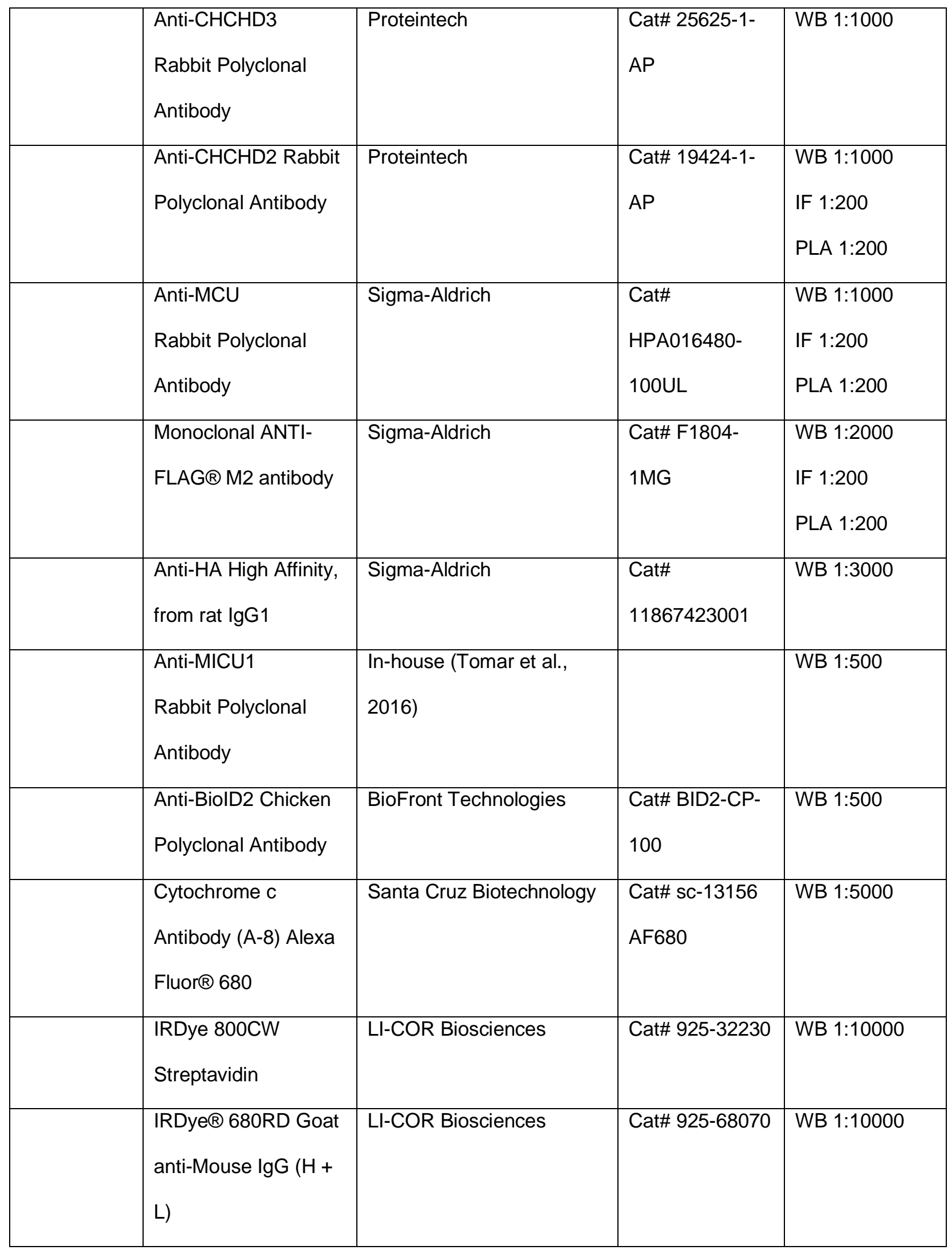




\begin{tabular}{|c|c|c|c|c|}
\hline & $\begin{array}{l}\text { IRDye } \AA \text { 680RD Goat } \\
\text { anti-Rat } \lg G(H+L)\end{array}$ & LI-COR Biosciences & Cat\# 925-68076 & WB $1: 10000$ \\
\hline & $\begin{array}{l}\text { IRDye® 680RD Goat } \\
\text { anti-Rabbit lgG }(H+ \\
\text { L) }\end{array}$ & LI-COR Biosciences & Cat\# 926-68071 & WB 1:10000 \\
\hline & $\begin{array}{l}\text { Goat Anti-Chicken } \\
\text { IgY H\&L (Alexa } \\
\text { Fluor® 680) }\end{array}$ & Abcam & Cat\# ab175779 & WB 1:10000 \\
\hline & $\begin{array}{l}\text { IR Dye Goat anti } \\
\text { Rabbit } 800 \mathrm{CW}\end{array}$ & LI-COR Biosciences & Cat\# 926-32211 & WB 1:10000 \\
\hline & $\begin{array}{l}\text { IRDye® 800CW Goat } \\
\text { anti-Mouse lgG (H + } \\
\text { L) }\end{array}$ & LI-COR Biosciences & Cat\# 926-32210 & WB 1:10000 \\
\hline & $\begin{array}{l}\text { Donkey anti-Mouse } \\
\text { lgG }(\mathrm{H}+\mathrm{L}) \text { Highly } \\
\text { Cross-Adsorbed } \\
\text { Secondary Antibody, } \\
\text { Alexa Fluor } 488\end{array}$ & Thermo Fisher Scientific & Cat\# A-21202 & IF 1:500 \\
\hline & $\begin{array}{l}\text { Goat anti-Rabbit lgG } \\
(\mathrm{H}+\mathrm{L}) \text { Highly Cross- } \\
\text { Adsorbed Secondary } \\
\text { Antibody, Alexa Fluor } \\
\text { Plus } 647\end{array}$ & Thermo Fisher Scientific & Cat\# A32733 & IF 1:500 \\
\hline \multirow[t]{2}{*}{$\begin{array}{l}\text { Magnetic } \\
\text { Beads }\end{array}$} & $\begin{array}{l}\text { ANTI-FLAG(R) M2 } \\
\text { MAGNETIC BEADS }\end{array}$ & Sigma-Aldrich & $\begin{array}{l}\text { Cat\# M8823- } \\
1 \mathrm{ML}\end{array}$ & \\
\hline & $\begin{array}{l}\text { DYNAL MyOne } \\
\text { Dynabeads }\end{array}$ & Thermo Fisher Scientific & Cat\# 65-001 & \\
\hline
\end{tabular}




\begin{tabular}{|c|c|c|c|c|}
\hline & Streptavidin C1 & & & \\
\hline \multirow[t]{2}{*}{$\begin{array}{l}\text { Commercial } \\
\text { assay or kit }\end{array}$} & $\begin{array}{l}\text { Duolink® In Situ Red } \\
\text { Starter Kit } \\
\text { Mouse/Rabbit }\end{array}$ & Sigma-Aldrich & $\begin{array}{l}\text { Cat\# } \\
\text { DUO92101-1KT }\end{array}$ & PLA \\
\hline & $\begin{array}{l}\text { Recombinant Human } \\
\text { BID (Caspase-8- } \\
\text { cleaved) Protein, CF }\end{array}$ & R\&D Systems & $\begin{array}{l}\text { Cat\# 882-B8- } \\
050\end{array}$ & $\begin{array}{l}\text { Cytochrome c } \\
\text { release assay }\end{array}$ \\
\hline \multirow[t]{2}{*}{$\begin{array}{l}\text { Staining } \\
\text { reagents }\end{array}$} & Fura-FF & AAT Bioquest & Cat\# 21028 & $\mathrm{Ca}^{2+}$ detection \\
\hline & Hoechst 33342 & Thermo Fisher Scientific & Cat\# 62249 & $\begin{array}{l}\text { Nucleus } \\
\text { Staining }\end{array}$ \\
\hline \multirow[t]{3}{*}{$\begin{array}{l}\text { Software, } \\
\text { algorithm }\end{array}$} & $\begin{array}{l}\text { GraphPad } \\
\text { Prism }\end{array}$ & https://www.graphpad.com/ & & \\
\hline & Image J Fiji & https://imagej.net/Fiji & & \\
\hline & Zeiss Zen & https://www.zeiss.com & & \\
\hline
\end{tabular}

\section{Plasmids Construction}

213 To generate Start-BiolD2-HA plasmid, BiolD2 was PCR-amplified from the MCS-BioID2-HA

214 plasmid using primers designed to introduce an ATG start codon immediately downstream of

215 the BamHI restriction site of the MCS. The PCR product was cloned via BamHI and HindIII into

216 the MCS-BiolD2-HA plasmid (Addgene \#74224). To generate the MICU1-BioID2-HA, MICU1

217 was PCR amplified from the hMICU1-Myc-DDK plasmid using primers to introduce a 5' Agel

218 and a 3' BamHI restriction site. The PCR product was cloned via Agel and BamHI into the MCS-

219 BiolD2-HA plasmid (Addgene \#74224). MICU1-HA plasmid was generated by cleaving the

220 MICU1 fragment from the MICU1-FLAG plasmid using the Sgfl-Mlul restriction sites and

221 inserted at the same sites in PCMV6-AC-HA vector. All plasmids were confirmed using the

222 restriction digestion and DNA sequencing. 


\section{Cell culture}

224 HEK293T WT, HEK293T MCU ${ }^{/-}$and HEK293T MICU1/- cells were grown in Dulbecco's

225 Modification of Eagle's Medium with $4.5 \mathrm{~g} / \mathrm{L}$ glucose, L-glut, and Na Pyr medium (Corning

226 Cellgro, Cat\#10-013-CV) supplemented with 10\% fetal bovine serum (Peak Serum, Cat\#PS-

227 FB3), 1\% penicillin/streptomycin (Sigma-Aldrich, Cat\# P0781-100ML) at $37^{\circ} \mathrm{C}$ in the presence of

$2285 \% \mathrm{CO}_{2}$. Mouse embryonic fibroblasts isolated from the Micu ${ }^{\text {fl/fl }}$ mouse were immortalized by infecting the cells with SV40 large T antigen-expressing adenovirus. The immortalized Micu $1^{\mathrm{fl} / \mathrm{fl}}$ MEFs serve as $\mathrm{Micu}^{+/+}$control cells. Micu1/- MEFs were generated by transducing the $\mathrm{Micu}^{+/+}$MEFs with adenovirus encoding Cre-recombinase (Ad-Cre). MEFs were grown in Dulbecco's Modification of Eagle's Medium with $4.5 \mathrm{~g} / \mathrm{L}$ glucose, L-glut, and Na Pyr medium

233 (Corning Cellgro, Cat\#10-013-CV) supplemented with 10\% fetal bovine serum (Peak Serum, 234 Cat\#PS-FB3), 1\% Gibco® MEM Non-Essential Amino Acids (Thermo Fisher Scientific, Cat\# 11140-050), 1\% penicillin/streptomycin (Sigma-Aldrich, Cat\# P0781-100ML), at $37^{\circ} \mathrm{C}$ in the presence of $5 \% \mathrm{CO}_{2}$. The $\mathrm{Chchd}^{+/+}$and $\mathrm{Chchd}^{/-}$MEFs were cultured as described earlier

237 (Meng et al., 2017). To exogenously express MICU1, MIC60, CHCHD3, and CHCHD2,

238 HEK293T cells were transfected with the Fugene HD transfection reagent (Promega,

239 Cat\#E2311) as per manufacturer instruction. To generate the MEFs stably expressing MICU1-

240 FLAG, immortalized WT MEFs were transfected with MICU1-FLAG plasmid (OriGene

241 Technologies, Cat\#MR207652) using the Fugene HD transfection reagent (Promega,

242 Cat\#E2311). 24h post-transfection, culture media was replaced with media supplemented with

243 the $500 \mu \mathrm{g} / \mathrm{mL}$ G418 (Thermo Fisher Scientific, Cat\#10131035). Fresh culture media

244 supplemented with G418 was replaced at two-day interval, until all the dying cells were cleared.

245 After incubation for two weeks, the cells were maintained in DMEM supplemented with 200

$246 \mu \mathrm{g} / \mathrm{mL}$ G418. The protein expression was validated by western blotting and

247 immunofluorescence. 


\section{Immunoblotting}

249 Cells were harvested, washed with ice-cold PBS and lysed in 1X RIPA lysis buffer (EMD

250 Millipore, Cat\#20-188) supplemented with SIGMAFASTTM Protease Inhibitor Cocktail (Sigma-

251 Aldrich, Cat\#S8830). Protein concentrations were determined by Pierce 660nm Protein Assay

252 (Thermo Fisher Scientific, Cat\#22660) and equal ug of protein were separated by

253 electrophoresis on NuPAGE 4-12\% Bis-Tris protein gel (Thermo Fisher Scientific,

254 Cat\#WG1402BOX), in denaturing conditions. Protein was electroblotted on PVDF membrane

255 (EMD Millipore, Cat\#IPFL00010). Following the transfer, the membrane was incubated in

256 Blocking Buffer (Rockland, Cat\#MB-070) for $1 \mathrm{~h}$ at room temperature, followed by overnight

257 incubation with specific primary antibody at $4^{\circ} \mathrm{C}$. After incubation the membrane was washed

258 with TBS-T (TBS containing 0.1\% Tween 20) 3 times for 10 min each and then incubated with

259 specific secondary antibody for $1 \mathrm{~h}$ at room temperature. The membrane was similarly washed 3

260 times with TBS-T and then imaged on an LI-COR Odyssey system.

\section{Sub-mitochondrial protein localization assay}

262 Mitochondria were isolated as described earlier (Tomar et al., 2015). Briefly, cells were grown in

$263150 \mathrm{~mm}^{2}$ culture dishes, washed with PBS, and resuspended in isotonic mitochondria isolation

264 buffer (10 mM HEPES, pH 7.5, containing 200 mM mannitol, 70 mM sucrose, and 1 mM EGTA).

265 The cell suspension was homogenized by Dounce homogenizer, centrifuged at $500 \mathrm{~g}$ for $10 \mathrm{~min}$

266 at $4^{\circ} \mathrm{C}$. Supernatant was collected and centrifuged at $12,000 \mathrm{~g}$ for $15 \mathrm{~min}$ at $4^{\circ} \mathrm{C}$ to obtain crude

267 mitochondrial pellet. The pellet was resuspended in mitochondria isolation buffer and washed 2

268 times using the centrifuge at $12,000 \mathrm{~g}$ for $15 \mathrm{~min}$ at $4^{\circ} \mathrm{C}$. The mitochondrial pellet was

269 resuspended in intracellular buffer $(120 \mathrm{mM} \mathrm{KCl}, 10 \mathrm{mM} \mathrm{NaCl}, 1 \mathrm{mM} \mathrm{KH} 2 \mathrm{PO}$, 20 mM HEPES-

270 Tris, $\mathrm{pH}$ 7.2) and permeabilized with varying digitonin concentrations and digested with

271 proteinase $\mathrm{K}(10 \mu \mathrm{g} / \mathrm{mL})$ for $10 \mathrm{~min}$ at room temperature. Proteinase $\mathrm{K}$ digestion was stopped by

272 adding SIGMAFAST ${ }^{\text {TM }}$ Protease Inhibitor Cocktail (Sigma-Aldrich, Cat\#S8830) and 2X SDS- 
273 loading dye and heating the samples at $95^{\circ} \mathrm{C}$ for $10 \mathrm{~min}$. The immunoblotting was performed

274 using specified antibodies.

\section{Biotinylation and mass spectrometry analysis}

276 To induce BiolD2-mediated protein biotinylation, cells were cultured with media supplemented

277 with $50 \mu \mathrm{M}$ biotin for $16 \mathrm{~h}$. Cells were collected, washed with PBS 2 times, and lysed in BiolD2

278 lysis buffer (50 mM Tris, $\mathrm{pH} 7.4,500 \mathrm{mM} \mathrm{NaCl}, 2 \%$ Triton X-100, 0.4\% SDS, $1 \mathrm{mM}$

279 dithiothreitol) supplemented with SIGMAFASTTM Protease Inhibitor Cocktail (Sigma-Aldrich,

280 Cat\#S8830). The cell suspension was sonicated for 2 times each for $1 \mathrm{~min}$ at an output level of

28140 (Vibra-Cell, Sonics). An equal volume of $50 \mathrm{mM}$ Tris, $\mathrm{pH}$ 7.4, was added and the suspension

282 was cleared using centrifugation at $16,500 \mathrm{~g}$ for $20 \mathrm{~min}$. The supernatant was used for

283 immunoblotting or Streptavidin based pull-down using MyOne Dynabeads Streptavidin C1.

284 Mass spectroscopy for identification of the biotinylated proteinss was performed as described

285 earlier (Kim et al., 2016).

\section{FPLC and protein fractionation}

287 Size-exclusion gel filtration was used to separate the high-molecular-weight protein complexes 288 using the fast protein liquid chromatography (ÄKTA Pure FPLC; GE Healthcare) (Tomar et al., 289 2016). The PBS-equilibrated Superdex 200 10/300 column (GE Healthcare, Cat\#17517501)

290 was calibrated with a gel filtration calibration standard (Bio-Rad, Cat\#1511901). The cleared cell

291 lysates were directly loaded onto FPLC and fractioned at a flow rate of $0.5 \mathrm{~mL} / \mathrm{min}$. Protein

292 fractions were collected in $0.5 \mathrm{~mL}$ PBS, concentrated to $50 \mu \mathrm{L}$ volume using an AMICON Ultra-

2930.5 Centrifugal Filter Devices (with a 3,000 kD cutoff) (EMD Millipore, Cat\#UFC500396).

294 Concentrated fractions were then immunoblotted using specific antibodies.

\section{Co-immunoprecipitation}


296 To study protein-protein interactions, immunoprecipitation experiments were performed as

297 described earlier (Tomar et al., 2016). Briefly, HEK293T cells were co-transfected with the

298 indicated plasmids. After $36 \mathrm{~h}$ of transfection, cells were harvested, washed with ice-cold PBS

299 and lysed in 1X RIPA lysis buffer (EMD Millipore, Cat\#20-188) supplemented with

300 SIGMAFASTTM Protease Inhibitor Cocktail (Sigma-Aldrich, Cat\#S8830). Protein concentrations

301 were determined by Pierce 660nm Protein Assay (Thermo Fisher Scientific, Cat\#22660) and

302 equal proteins amounts were used for co-immunoprecipitation. Cleared cell lysate was

303 incubated with Anti-FLAG M2 Magnetic Beads (Sigma-Aldrich) on a roller shaker overnight at

$3044^{\circ} \mathrm{C}$. Beads were washed 3 times with RIPA buffer and 2 times with TBS-T, resuspended in $2 \mathrm{X}$

305 SDS-PAGE sample buffers, and then immunoblotting was performed using specific antibodies.

\section{Co-immunofluorescence}

307 The mitochondrial localization of mtCU, MICOS, and MICU1 was also analyzed by

308 immunofluorescence using standard protocol (Tomar et al., 2015). Briefly, the MEFs stably

309 expressing MICU1-FLAG were grown on collagen-coated 35-mm dishes. Cells were washed

310 with PBS, fixed for 20 min with $4 \%$ paraformaldehyde, then permeabilized for $15 \mathrm{~min}$ by $0.15 \%$

311 Triton X-100. Permeabilized cells were blocked using 10\% BSA for 45min at room temperature

312 and incubated with primary antibodies overnight at $4^{\circ} \mathrm{C}$. After incubation, cells were washed 3

313 times with blocking reagent and incubated with Alexa Fluor-tagged secondary antibodies for $1 \mathrm{~h}$

314 at room temperature. Cells were washed 3 times with PBS, and confocal images were obtained

315 using an LSM 510 META Laser Scanning Microscope (Carl Zeiss, Inc.) at 488- and 647-nm

316 excitations using a 63x oil objective. Images were analyzed and quantitated using ZEN 2010

317 software (Carl Zeiss, Inc.), and Image J Fiji. 
Proximity ligation assay (PLA) was used to detect in situ MICU1: MICOS interactions. MICU1FLAG expressing MEFs were seeded on collagen-coated 35-mm dishes. Cells were washed with PBS, fixed for 20 min with $4 \%$ paraformaldehyde, then permeabilized with $0.15 \%$ Triton X100. PLA was performed as per manufacturer's instructions (Sigma-Aldrich, Duolink® In Situ

323 Red Mouse/Rabbit Assay). Images were acquired using an LSM 510 META Laser Scanning

324 Microscope (Carl Zeiss, Inc.) using a 63x oil objective.

325

\section{Transmission electron microscopy}

Transmission electron microscopy (TEM) was utilized to evaluate mitochondrial ultrastructure and cristae organization. HEK293T cells of the indicated genotypes were grown to $80 \%$ confluency on $25 \mathrm{~mm}$ diameter Thermanox® Cover Slips (Thermo Fisher Scientific, Cat\#174985PK) in 6-well plates. Culture media was removed, and cells were fixed with freshly prepared TEM fixation buffer ( $2 \%$ glutaraldehyde, $2 \%$ paraformaldehyde in $0.1 \mathrm{M}$ sodium cacodylate buffer) for $30 \mathrm{~min}$ at room temperature. Fixative was replaced with $0.1 \mathrm{M}$ sodium cacodylate buffer, and then samples were processed for TEM imaging. Images were obtained using Zeiss LIBRA120 TEM equipped with Gatan UltraScan, 1000 2k x 2k CCD EFTEM, energy filtering. Images were analyzed and quantitated Image J Fiji.

\section{Cytochrome c release assay}

The cytochrome c release assay was performed as described earlier (Tomar et al., 2015) with slight modifications. Briefly, MEFs of indicated genotypes were grown in $150 \mathrm{~mm}^{2}$ culture dishes. Cells were washed with ice-cold PBS, pH 7.4. An equal number of cells were suspended in intracellular buffer (120 mM KCl, 10 mM NaCl, 1 mM KH2PO4, 20 mM HEPES-Tris, pH 7.2) supplemented with SIGMAFASTTM Protease Inhibitor Cocktail (Sigma-Aldrich, Cat\#S8830), and permeabilized with digitonin $(80 \mu \mathrm{g} / \mathrm{mL})$ for $5 \mathrm{~min}$ at room temperature. The cytochrome $\mathrm{C}$ release was induced by adding $\mathrm{tBid}(20 \mathrm{nM})$ and incubating the cell suspension at $30^{\circ} \mathrm{C}$ for 
$34330 \mathrm{~min}$. Cell homogenates were spun at $16,500 \mathrm{~g}, 4^{\circ} \mathrm{C}$ for $10 \mathrm{~min}$, and the supernatant

344 (cytosolic fraction) was removed. Pellets were lysed 1XRIPA buffer and centrifuged at 16,500 g,

$3454^{\circ} \mathrm{C}$ for $10 \mathrm{~min}$ to obtain the total cell lysate. Both total cell lysate and cytosolic fractions were

346 immunoblotted using the cytochrome c antibody.

\section{$347 \quad \mathrm{Ca}^{2+}$ flux analysis}

$348 \mathrm{mCa}^{2+}$ flux was analyzed as described earlier (Luongo et al., 2015; Tomar et al., 2016). Briefly, 349 cells were washed in $\mathrm{Ca}^{2+}$-free DPBS (Thermo Fisher Scientific, Cat\#14190235). An equal

350 number of cells $\left(7 \times 10^{6}\right.$ cells) were resuspended and permeabilized with $40 \mu \mathrm{g} / \mathrm{ml}$ digitonin in 1.5 $351 \mathrm{ml}$ of intracellular medium (120 mM KCl, $10 \mathrm{mM} \mathrm{NaCl}, 1 \mathrm{mM} \mathrm{KH2PO4,} 20 \mathrm{mM}$ HEPES-Tris, pH

352 7.2), containing $2 \mu \mathrm{M}$ thapsigargin to block the SERCA pump, and supplemented with $5 \mathrm{mM}$

353 succinate. Fura-FF $(1 \mu \mathrm{M})$ was loaded to the cell suspension, and fluorescence was monitored in

354 a multiwavelength excitation dual-wavelength emission fluorimeter (Delta RAM, PTI).

355 Extramitochondrial $\mathrm{Ca}^{2+}$ is shown as the excitation ratio $(340 \mathrm{~nm} / 380 \mathrm{~nm})$ of Fura-FF

356 fluorescence. $\mathrm{A} \mathrm{Ca}^{2+}$ bolus, and then mitochondrial uncoupler, FCCP $(2 \mu \mathrm{M})$, were added at the

357 indicated time points $(8,9)$. All the experiments were performed at $37^{\circ} \mathrm{C}$ with constant stirring.

\section{Statistical analysis}

359 Results are presented as mean +/- standard error of the mean. Statistical analysis was 360 performed using GraphPad PRISM 7.05 (Graph Pad Software). All experiments were repeated

361 independently at least three times. Column analyses were performed using an unpaired, 2-tailed

362 t-test (for 2 groups) with Welch's correction. For grouped analyses, 2-way ANOVA with Tukey

363 post-hoc analysis was performed. $P$ values less than 0.05 (95\% confidence interval) were

364 considered significant.

\section{Data availability.}

366 All relevant data are available from the authors. 


\section{Acknowledgments}

368 The authors thanks to Trevor Tierney for technical and managerial assistance in the Elrod

369 Laboratory.

370 Sources of Funding

371 NIH to J.W.E.: R01HL142271, R01HL136954, R01HL123966, P01HL134608-sub-5483; AHA to

372 D.T.: 17POST33660251, 19CDA34490009.

\section{Author Contributions}

374 Conceptualization, D.T. and J.W.E.; Methodology, D.T., M.T., J.F.G., D.W.K., O.S., P.J., A.C.C.,

375 and J.W.E.; Investigation, D.T., M.T., O.S., P.J., and J.W.E; Resources, D.T., J.F.G., D.W.K.,

376 and J.W.E.; Writing - Original Draft, D.T. and J.W.E; Writing -Review \& Editing, D.T., M.T.,

377 J.F.G., P.J., and J.W.E.; Supervision, J.W.E.; Funding Acquisition, D.T., and J.W.E.

\section{$378 \quad$ Competing Interests}

379 The authors declare no competing interests.

\section{Author Information}

381 Correspondence and requests for materials should be addressed to J.W.E. (elrod@temple.edu). 


\section{References}

383

384

385

386

387

388

389

390

391

392

393

394

395

396

397

398

399

400

401

402

403

404

405

406

407

408

409

410

411

412

413

414

415

416

Antony, A.N., Paillard, M., Moffat, C., Juskeviciute, E., Correnti, J., Bolon, B., Rubin, E., Csordas, G., Seifert, E.L., Hoek, J.B., et al. (2016). MICU1 regulation of mitochondrial Ca(2+) uptake dictates survival and tissue regeneration. Nat Commun 7, 10955.

Bagur, R., and Hajnoczky, G. (2017). Intracellular Ca(2+) Sensing: Its Role in Calcium Homeostasis and Signaling. Mol Cell 66, 780-788.

Baughman, J.M., Perocchi, F., Girgis, H.S., Plovanich, M., Belcher-Timme, C.A., Sancak, Y., Bao, X.R., Strittmatter, L., Goldberger, O., Bogorad, R.L., et al. (2011). Integrative genomics identifies MCU as an essential component of the mitochondrial calcium uniporter. Nature 476, 341-345.

Bick, A.G., Wakimoto, H., Kamer, K.J., Sancak, Y., Goldberger, O., Axelsson, A., DeLaughter, D.M., Gorham, J.M., Mootha, V.K., Seidman, J.G., et al. (2017). Cardiovascular homeostasis dependence on MICU2, a regulatory subunit of the mitochondrial calcium uniporter. Proc Natl Acad Sci U S A 114, E9096-E9104.

Carafoli, E. (2002). Calcium signaling: a tale for all seasons. Proc Natl Acad Sci U S A 99, 11151122.

Carafoli, E. (2003). The calcium-signalling saga: tap water and protein crystals. Nat Rev Mol Cell Biol 4, 326-332.

Csordas, G., Golenar, T., Seifert, E.L., Kamer, K.J., Sancak, Y., Perocchi, F., Moffat, C., Weaver, D., de la Fuente Perez, S., Bogorad, R., et al. (2013). MICU1 controls both the threshold and cooperative activation of the mitochondrial $\mathrm{Ca}(2)(+)$ uniporter. Cell Metab 17, 976-987.

De Stefani, D., Raffaello, A., Teardo, E., Szabo, I., and Rizzuto, R. (2011). A forty-kilodalton protein of the inner membrane is the mitochondrial calcium uniporter. Nature 476, 336-340.

Fransson, A., Ruusala, A., and Aspenstrom, P. (2003). Atypical Rho GTPases have roles in mitochondrial homeostasis and apoptosis. J Biol Chem 278, 6495-6502.

Frederick, R.L., McCaffery, J.M., Cunningham, K.W., Okamoto, K., and Shaw, J.M. (2004). Yeast Miro GTPase, Gem1p, regulates mitochondrial morphology via a novel pathway. J Cell Biol 167, 87-98.

Friedman, J.R., Mourier, A., Yamada, J., McCaffery, J.M., and Nunnari, J. (2015). MICOS coordinates with respiratory complexes and lipids to establish mitochondrial inner membrane architecture. Elife 4.

Gottschalk, B., Klec, C., Waldeck-Weiermair, M., Malli, R., and Graier, W.F. (2018). Intracellular $\mathrm{Ca}(2+)$ release decelerates mitochondrial cristae dynamics within the junctions to the endoplasmic reticulum. Pflugers Arch 470, 1193-1203. 
Greenawalt, J.W., Rossi, C.S., and Lehninger, A.L. (1964). Effect of Active Accumulation of Calcium and Phosphate lons on the Structure of Rat Liver Mitochondria. J Cell Biol 23, 21-38. Mann, M., Reggiori, F., and Neupert, W. (2011). The mitochondrial contact site complex, a determinant of mitochondrial architecture. EMBO J 30, 4356-4370.

422 Hoffman, N.E., Chandramoorthy, H.C., Shamugapriya, S., Zhang, X., Rajan, S.,

423 Mallilankaraman, K., Gandhirajan, R.K., Vagnozzi, R.J., Ferrer, L.M., Sreekrishnanilayam, K., et 424 al. (2013). MICU1 motifs define mitochondrial calcium uniporter binding and activity. Cell Rep 5, $425 \quad 1576-1588$.

426 Kim, D.I., Jensen, S.C., Noble, K.A., Kc, B., Roux, K.H., Motamedchaboki, K., and Roux, K.J. 427 (2016). An improved smaller biotin ligase for BiolD proximity labeling. Mol Biol Cell 27, 11884281196.

429 Kirichok, Y., Krapivinsky, G., and Clapham, D.E. (2004). The mitochondrial calcium uniporter is 430 a highly selective ion channel. Nature 427, 360-364.

431 Lewis-Smith, D., Kamer, K.J., Griffin, H., Childs, A.M., Pysden, K., Titov, D., Duff, J., Pyle, A., 432 Taylor, R.W., Yu-Wai-Man, P., et al. (2016). Homozygous deletion in MICU1 presenting with 433 fatigue and lethargy in childhood. Neurol Genet 2, e59.

434 Liu, J.C., Liu, J., Holmstrom, K.M., Menazza, S., Parks, R.J., Fergusson, M.M., Yu, Z.X., 435 Springer, D.A., Halsey, C., Liu, C., et al. (2016). MICU1 Serves as a Molecular Gatekeeper to 436 Prevent In Vivo Mitochondrial Calcium Overload. Cell Rep 16, 1561-1573.

437 Logan, C.V., Szabadkai, G., Sharpe, J.A., Parry, D.A., Torelli, S., Childs, A.M., Kriek, M., 438 Phadke, R., Johnson, C.A., Roberts, N.Y., et al. (2014). Loss-of-function mutations in MICU1 cause a brain and muscle disorder linked to primary alterations in mitochondrial calcium 440 signaling. Nat Genet 46, 188-193.

441 Luongo, T.S., Lambert, J.P., Yuan, A., Zhang, X., Gross, P., Song, J., Shanmughapriya, S., 442 Gao, E., Jain, M., Houser, S.R., et al. (2015). The Mitochondrial Calcium Uniporter Matches 443 Energetic Supply with Cardiac Workload during Stress and Modulates Permeability Transition. $444 \quad$ Cell Rep 12, 23-34.

Mallilankaraman, K., Cardenas, C., Doonan, P.J., Chandramoorthy, H.C., Irrinki, K.M., Golenar, component of mitochondrial Ca2+ uptake that regulates cellular metabolism. Nat Cell Biol 14, 1336-1343.

449 Mallilankaraman, K., Doonan, P., Cardenas, C., Chandramoorthy, H.C., Muller, M., Miller, R., 450 Hoffman, N.E., Gandhirajan, R.K., Molgo, J., Birnbaum, M.J., et al. (2012b). MICU1 is an 451 essential gatekeeper for MCU-mediated mitochondrial $\mathrm{Ca}(2+)$ uptake that regulates cell 452 survival. Cell 151, 630-644.

453 Meng, H., Yamashita, C., Shiba-Fukushima, K., Inoshita, T., Funayama, M., Sato, S., Hatta, T., 454 Natsume, T., Umitsu, M., Takagi, J., et al. (2017). Loss of Parkinson's disease-associated 
protein $\mathrm{CHCHD} 2$ affects mitochondrial crista structure and destabilizes cytochrome c. Nat Commun 8, 15500.

Nemani, N., Carvalho, E., Tomar, D., Dong, Z., Ketschek, A., Breves, S.L., Jana, F., Worth, A.M., Heffler, J., Palaniappan, P., et al. (2018). MIRO-1 Determines Mitochondrial Shape Transition upon GPCR Activation and $\mathrm{Ca}(2+)$ Stress. Cell Rep 23, 1005-1019.

Paillard, M., Csordas, G., Huang, K.T., Varnai, P., Joseph, S.K., and Hajnoczky, G. (2018). MICU1 Interacts with the D-Ring of the MCU Pore to Control Its $\mathrm{Ca}(2+)$ Flux and Sensitivity to Ru360. Mol Cell 72, 778-785 e773.

Patron, M., Checchetto, V., Raffaello, A., Teardo, E., Vecellio Reane, D., Mantoan, M., Granatiero, V., Szabo, I., De Stefani, D., and Rizzuto, R. (2014). MICU1 and MICU2 finely tune the mitochondrial Ca2+ uniporter by exerting opposite effects on MCU activity. Mol Cell 53, 726737.

Perocchi, F., Gohil, V.M., Girgis, H.S., Bao, X.R., McCombs, J.E., Palmer, A.E., and Mootha, V.K. (2010). MICU1 encodes a mitochondrial EF hand protein required for $\mathrm{Ca}(2+)$ uptake. Nature 467, 291-296.

Phillips, C.B., Tsai, C.W., and Tsai, M.F. (2019). The conserved aspartate ring of MCU mediates MICU1 binding and regulation in the mitochondrial calcium uniporter complex. Elife 8.

Plovanich, M., Bogorad, R.L., Sancak, Y., Kamer, K.J., Strittmatter, L., Li, A.A., Girgis, H.S., Kuchimanchi, S., De Groot, J., Speciner, L., et al. (2013). MICU2, a paralog of MICU1, resides within the mitochondrial uniporter complex to regulate calcium handling. PLoS One 8, e55785.

Raffaello, A., De Stefani, D., Sabbadin, D., Teardo, E., Merli, G., Picard, A., Checchetto, V., Moro, S., Szabo, I., and Rizzuto, R. (2013). The mitochondrial calcium uniporter is a multimer that can include a dominant-negative pore-forming subunit. EMBO J 32, 2362-2376.

Rizzuto, R., De Stefani, D., Raffaello, A., and Mammucari, C. (2012). Mitochondria as sensors and regulators of calcium signalling. Nat Rev Mol Cell Biol 13, 566-578.

Rizzuto, R., and Pozzan, T. (2006). Microdomains of intracellular Ca2+: molecular determinants and functional consequences. Physiol Rev 86, 369-408.

Sancak, Y., Markhard, A.L., Kitami, T., Kovacs-Bogdan, E., Kamer, K.J., Udeshi, N.D., Carr, S.A., Chaudhuri, D., Clapham, D.E., Li, A.A., et al. (2013). EMRE is an essential component of the mitochondrial calcium uniporter complex. Science 342, 1379-1382.

Saotome, M., Safiulina, D., Szabadkai, G., Das, S., Fransson, A., Aspenstrom, P., Rizzuto, R., and Hajnoczky, G. (2008). Bidirectional Ca2+-dependent control of mitochondrial dynamics by the Miro GTPase. Proc Natl Acad Sci U S A 105, 20728-20733.

Scorrano, L., Ashiya, M., Buttle, K., Weiler, S., Oakes, S.A., Mannella, C.A., and Korsmeyer, S.J. (2002). A distinct pathway remodels mitochondrial cristae and mobilizes cytochrome $C$ during apoptosis. Dev Cell 2, 55-67. 
491 Tadross, M.R., Dick, I.E., and Yue, D.T. (2008). Mechanism of local and global Ca2+ sensing by 492 calmodulin in complex with a Ca2+ channel. Cell 133, 1228-1240.

493 Tarasenko, D., Barbot, M., Jans, D.C., Kroppen, B., Sadowski, B., Heim, G., Mobius, W., 494 Jakobs, S., and Meinecke, M. (2017). The MICOS component Mic60 displays a conserved 495 membrane-bending activity that is necessary for normal cristae morphology. J Cell Biol 216, 496 889-899.

497 Tomar, D., Dong, Z., Shanmughapriya, S., Koch, D.A., Thomas, T., Hoffman, N.E., Timbalia, 498 S.A., Goldman, S.J., Breves, S.L., Corbally, D.P., et al. (2016). MCUR1 Is a Scaffold Factor for 499 the MCU Complex Function and Promotes Mitochondrial Bioenergetics. Cell Rep 15, 16735001685.

501 Tomar, D., Prajapati, P., Lavie, J., Singh, K., Lakshmi, S., Bhatelia, K., Roy, M., Singh, R., 502 Benard, G., and Singh, R. (2015). TRIM4; a novel mitochondrial interacting RING E3 ligase, 503 sensitizes the cells to hydrogen peroxide (H2O2) induced cell death. Free Radic Biol Med 89, 504 1036-1048.

505 Tufi, R., Gleeson, T.P., von Stockum, S., Hewitt, V.L., Lee, J.J., Terriente-Felix, A., Sanchez506 Martinez, A., Ziviani, E., and Whitworth, A.J. (2019). Comprehensive Genetic Characterization 507 of Mitochondrial $\mathrm{Ca}(2+)$ Uniporter Components Reveals Their Different Physiological 508 Requirements In Vivo. Cell Rep 27, 1541-1550 e1545.

509 van der Laan, M., Horvath, S.E., and Pfanner, N. (2016). Mitochondrial contact site and cristae 510 organizing system. Curr Opin Cell Biol 41, 33-42.

511 Xing, Y., Wang, M., Wang, J., Nie, Z., Wu, G., Yang, X., and Shen, Y. (2019). Dimerization of 512 MICU Proteins Controls $\mathrm{Ca}(2+)$ Influx through the Mitochondrial $\mathrm{Ca}(2+)$ Uniporter. Cell Rep 26, 513 1203-1212 e1204. 
515 Figure 1. Identification of $\mathrm{mtCU}$ independent MICU1 interactors. (A) Cleared cell lysates

516 isolated from WT and $M C U^{/-}$HEK293T cells were fractionated by FPLC-based size exclusion

517 chromatography. The protein fractions ranging from $\sim 10 \mathrm{kDa}$ to $\sim 900 \mathrm{kDa}$ were collected, concentrated, and subjected to immunoblotting using the MICU1 antibody. (B) Densitometry was performed to generate chromatographs of the MICU1 distribution in different fractions in Figure 1A. (C-D) MEFs stably expressing MICU1-FLAG were cultured on collagen-coated cover

521 glass, were fixed with 4\%PFA, and co-immunofluorescence was performed using FLAG and

522 MCU antibodies. Images were acquired using an LSM 510 META Laser Scanning Microscope

523 (Carl Zeiss, Inc.). Scale bar $C=10 \mu \mathrm{m}, \mathrm{C}$ inset $=5 \mu \mathrm{m}, \mathrm{D}=5 \mu \mathrm{m}$. (E) Experimental outline for the

524 utilization of MICU1-BioID2-HA fusion protein to identify the mtCU-independent MICU1

525 interactors via biotin-based proximity labeling. (F) HEK293T MICU1/- cells were transfected with

526 plasmids encoding BiolD2-HA, and MICU1-BiolD2-HA. Cells were cultured in the presence of

527 biotin $(50 \mu \mathrm{M})$ for $16 \mathrm{~h}$ to induce the biotinylation. Cells were collected, washed twice with PBS,

528 lysed in BiolD2 lysis buffer, western blotting with the indicated antibodies. (G) Mitochondria

529 were isolated from HEK293T MICU1 $^{-/-}$cells reconstituted with MICU1-BiolD2-HA. Mitochondrial

530 fractions were subjected to increasing digitonin concentrations to permeabilize the outer

531 mitochondrial membrane (OMM) and inner mitochondrial membrane (IMM). Proteinase $\mathrm{K}$

532 treatment was performed to cleave the exposed proteins, and mitochondrial fractions were

533 probed with indicated antibodies. (H) HEK293T MICU1 ${ }^{-/-}$and HEK293T $\mathrm{MCU}^{/-}$cells were

534 transfected with plasmids encoding BiolD2-HA or MICU1-BiolD2-HA. Cells were cultured in the

535 presence or absence of biotin $(50 \mu \mathrm{M})$ for $16 \mathrm{~h}$. Cells were collected, washed with PBS 2 times,

536 and lysed in BiolD2 lysis buffer. An aliquot of the lysates were subjected to western blotting

537 using the anti-BiolD2 antibody and Streptavidin to validate effective biotinylation of cellular

538 proteins. (I) Protein samples were subjected to Streptavidin based pull-down and digested with 
539 trypsin. LC-MS/MS analysis of $10 \%$ of total digests in duplicate runs was performed by on-line

540 analysis of peptides by a high-resolution, high-accuracy LC-MS/MS system (Thermo Fisher

541 Scientific). Estimated protein abundance after global sample normalization was used to

542 compare different groups.

543

544

545

546

547

548

549

550

551

552

553

554

555

556

557

558

559

560

561

562

563

Figure 2. MICU1 directly interacts with MICOS components and is essential for the formation of high-molecular-weight MICOS. (A) MICU1-HA and FLAG-tagged MICOS components co-expressed in the HEK293T MICU1 $1^{-/-}$cells. Cell lysates of equal protein content were subjected to FLAG-immunoprecipitation (IP), and IP products were probed with FLAG and HA antibodies to detect the interaction between MICU1 and MICOS components. (B-E) MICU1FLAG expressing MEFs were cultured on the collagen-coated cover glass and fixed with PFA, then co-immunofluorescence was performed using FLAG and MIC60 (B, C), or CHCHD2 (D, E) antibodies. Images were acquired using an LSM 510 META Laser Scanning Microscope (Carl Zeiss, Inc.). Merged images show the co-localization between the MICU1 and MIC60 or CHCHD2. Line scan shows the presence of MICU1 with both the MICOS components. Scale bar $B, D=10 \mu \mathrm{m} ; C$, E inset= $5 \mu \mathrm{m} .(\mathbf{F}, \mathbf{H})$ FPLC was performed using cleared cell lysates from WT, $\mathrm{MCU}^{/-}$, and MICU1 ${ }^{-/-} \mathrm{HEK} 293 \mathrm{~T}$ cells, and fractions were collected and subjected to western blotting using the MIC60 (F), and $\mathrm{CHCHD} 2(\mathrm{H})$ antibodies. The loss of MICU1 alters the size distribution of the multimeric MICOS complex. (G, I) Densitometry was performed to generate chromatographs of the MICOS components distribution in different molecular weight fractions in Figure $2 \mathrm{~F}$ and $2 \mathrm{H}$.

\section{Figure 3. $\mathrm{MICU1}^{-/-}$cells show altered cristae structure and enhanced cytochrome c} release. (A) WT and MICU1/- HEK293T cells were grown on Thermanox® Cover Slips and processed for the TEM imaging. Images were acquired by a Zeiss LIBRA120 TEM equipped with Gatan UltraScan, 1000 2k x 2k CCD EFTEM, energy filtering. MICU1 ${ }^{-/}$cells show distinct alterations in cristae organization and mitochondrial ultrastructure. Scale bar $=500 \mathrm{~nm}$. (B-F) 
564 TEM images were analyzed and quantitated using the Image J Fiji. Mitochondrial perimeter (B),

565 feret diameter (C), aspect ratio (D), inter-cristae junction distance (E), and cristae junction width

566 (F) were plotted. Statistical significance was determined using t-test. * indicates $\mathrm{p}<0.05 . \mathrm{n}=200$ -

567300 mitochondria. (G) Micu1 $1^{+/+}$and Micu $1^{-/-}$MEFs were grown in $150 \mathrm{~mm}^{2}$ culture dishes, and

568 cytochrome $\mathrm{c}$ release assay was performed. Micu $1^{-/-}$MEFs show enhanced basal and tBid-

569 induced cytochrome c release. (H) Densitometry was performed to quantify the cytochrome c

570 release in different groups in Figure 3G. Statistical significance was determined using t-test. *

571 indicates $p<0.05 . n=3$. 


\section{Supplementary Figure Legends}

573 Figure S1: (A) Western blot confirming the loss of MICU1 in Micu1 ${ }^{-1-}$ MEFs. (B) Representative

574 trace showing ${ }_{m} \mathrm{Ca}^{2+}$ uptake in WT and MICU1-1- HEK293T cells expressing BiolD2-HA, or

575 MICU1-BiolD2-HA fusion protein.

576 Figure S2: (A) MICU1-FLAG was reconstituted in MICU1/- HEK293T cells, and FLAG-IP was

577 performed to detect the interaction with endogenous MICOS components. (B) FPLC was

578 performed using cleared cell lysates from WT, $M C U^{{ }^{-}}$, and MICU1 $1^{-/-}$HEK293T cells, and

579 immunoblotted for CHCHD3. (C) Densitometry was performed to generate chromatographs of

580 the $\mathrm{CHCHD} 3$ distribution in different fractions from the cells shown in Figure S2B.

581 Figure S3. (A) Representative trace for $\mathrm{mCa}^{2+}$ influx/efflux in $\mathrm{Chchd2}^{+/+}$and $\mathrm{Chchd2}^{-/-} \mathrm{MEFs}$. (B-

582 C) ${ }_{\mathrm{m}} \mathrm{Ca}^{2+}$ uptake and efflux rate. (D-E) FPLC analysis for native MCU protein complexes

583 distribution in $C h c h d 2^{+/+}$and $C h c h d 2^{/-}$MEFs. The loss of Chchd2 does not have any effect on

584 the size distribution of the mtCU complex. 
bioRxiv preprint doi: https://doi.org/10.1101/803213; this version posted October 12, 2019. The copyright holder for this preprint (which was not certified by peer review) is the author/funder, who has granted bioRxiv a license to display the preprint in perpetuity. It is made available under aCC-BY-NC-ND 4.0 International license.

585 Table S1: MICU1 proximal MICOS components protein abundance in $\mathrm{MCU}^{+/+}$and $\mathrm{MCU}^{/-}$cells 
A

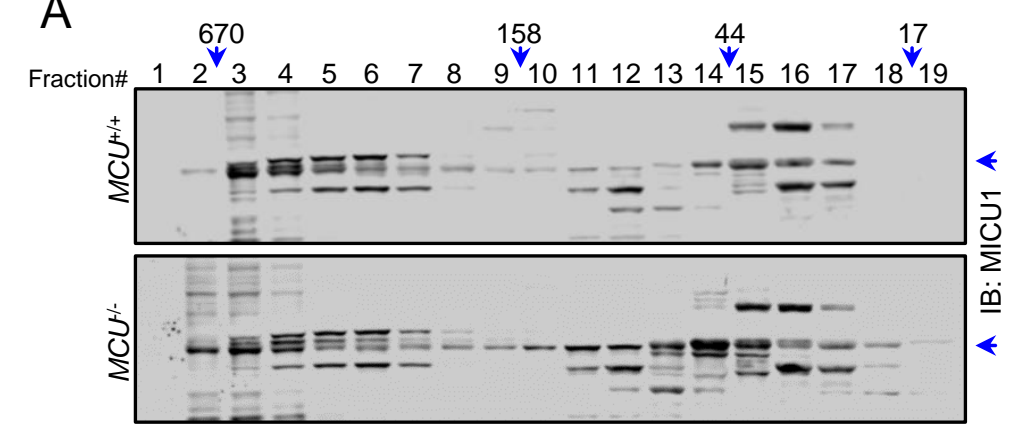

B
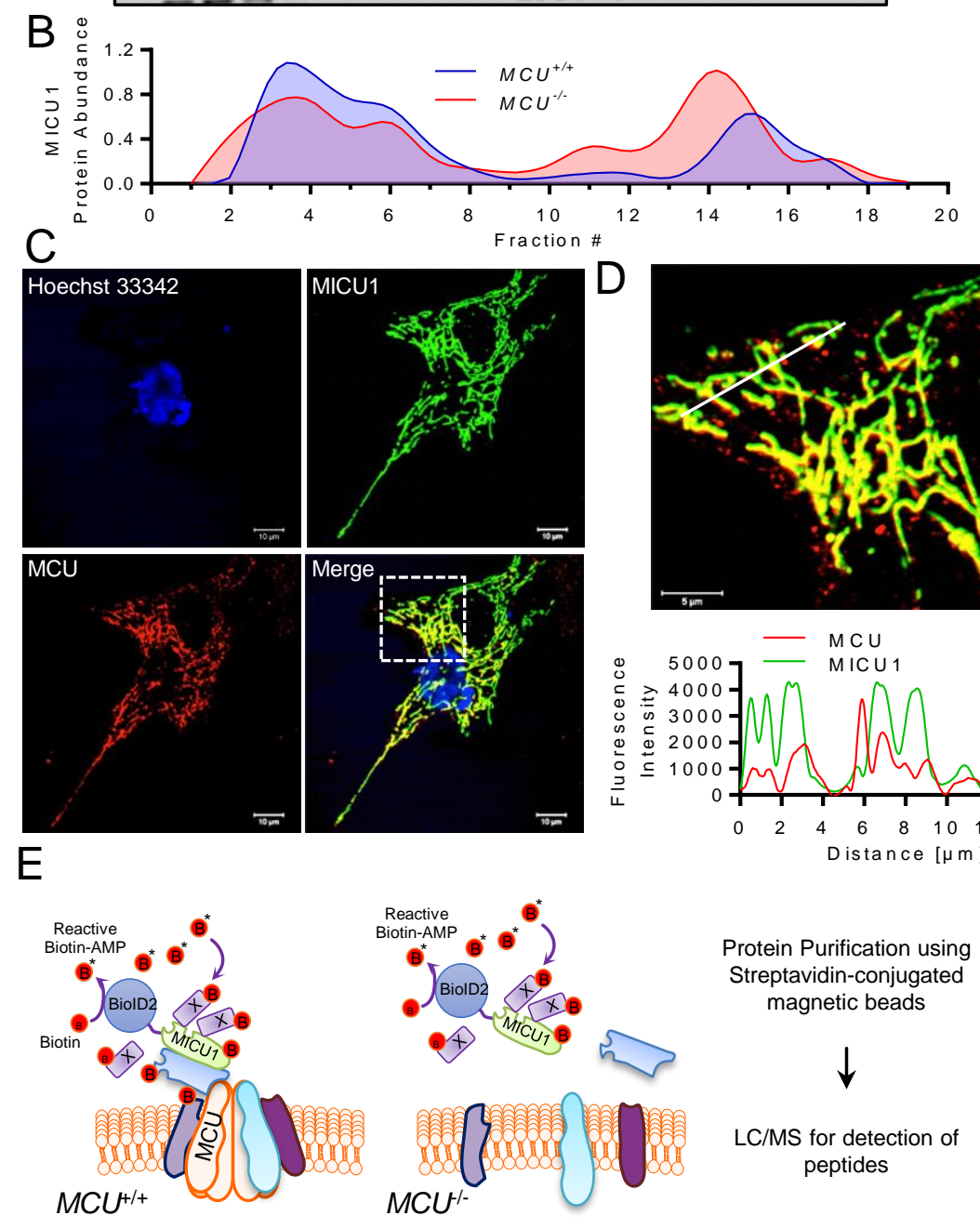

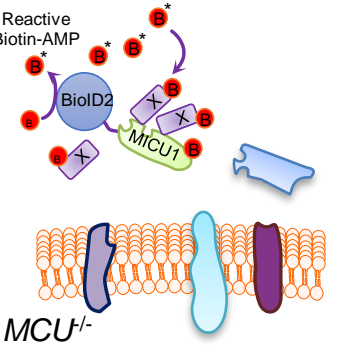

$F$ MICU1-

NT BiolD2-HA BiolD2-HA
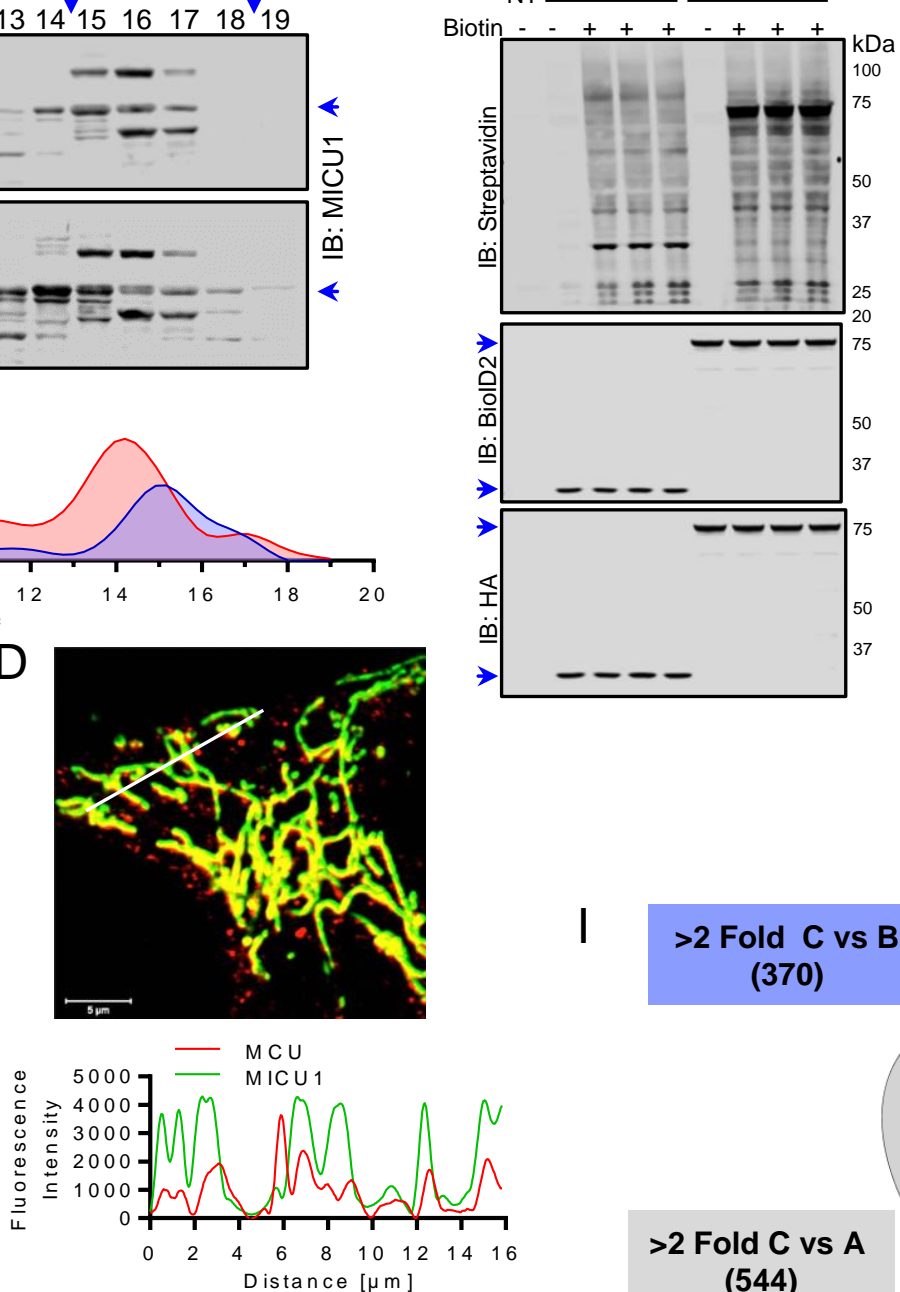

Protein Purification using Streptavidin-conjugated magnetic beads

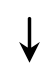

LC/MS for detection of peptides
G

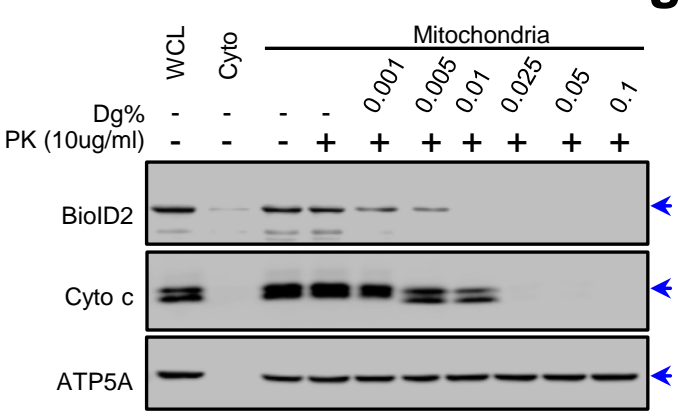

$\mathrm{H}$

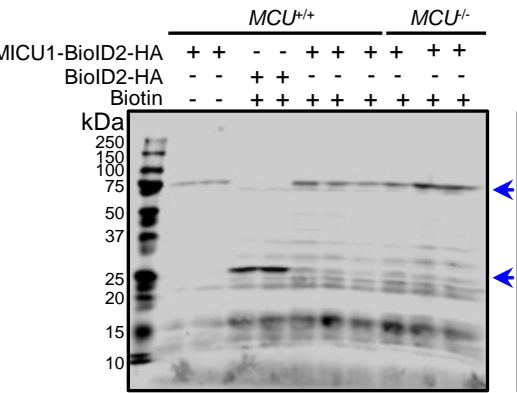

IB: BiolD2

$>2$ Fold C vs B (370)

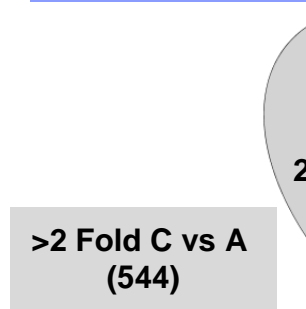

(544)

\section{1}

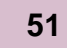

10

0

49

206

123

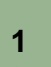

$97 \quad \begin{gathered}1 \\ \text { MICU1 }\end{gathered}$

$0 \quad 25$
Figure 1

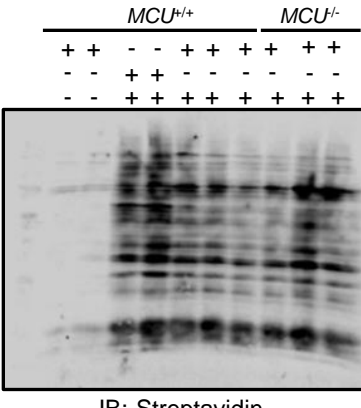

B: Streptavidin

$>2$ Fold C vs D

(282)

$>2$ Fold $D$ vs $C$

(109)
21

\begin{tabular}{|l|l|l|}
\hline \multicolumn{2}{|l|}{ Group } & Details \\
\hline A & $M C U^{+/+}$, MICU1-BiolD2-HA, No Biotin & Control for spurious biotinylation \\
\hline B & $M C U^{+/+}$, BiolD2-HA,+Biotin & Control for MICU1-independent biotinylation \\
\hline C & $M C U^{+/+}$, MICU1-BiolD2-HA, +Biotin & Total MICU1 interactome \\
\hline D & $M C U^{-/}$, MICU1-BiolD2-HA, +Biotin & MCU-independent MICU1 interactome \\
\hline
\end{tabular}




\section{Figure 3}

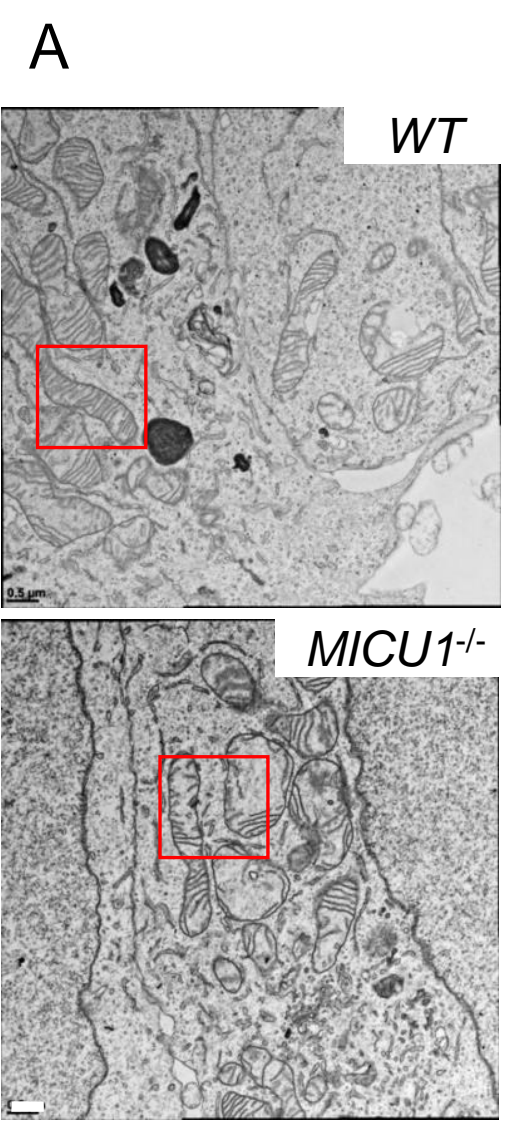

F

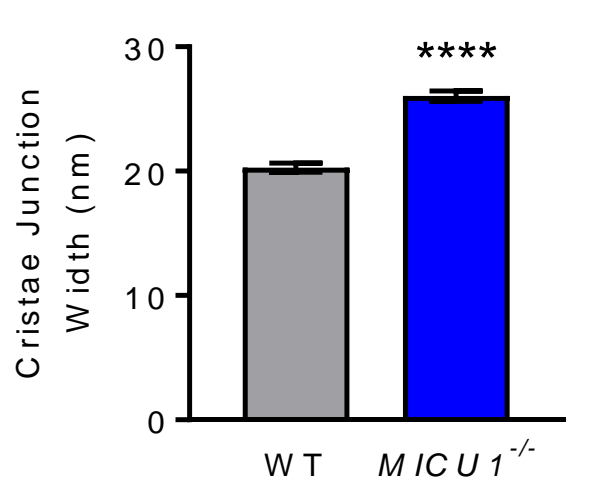

B

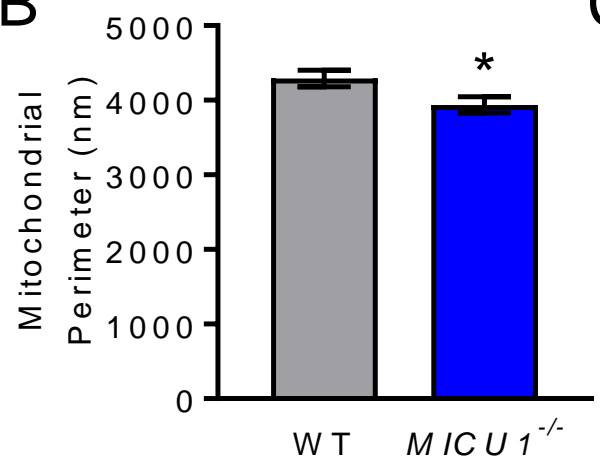

D

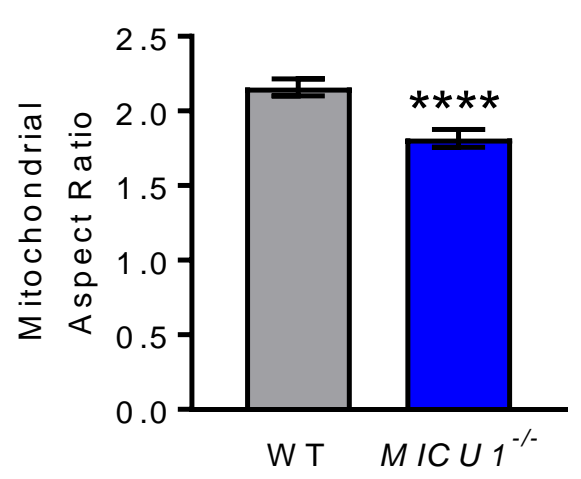

C

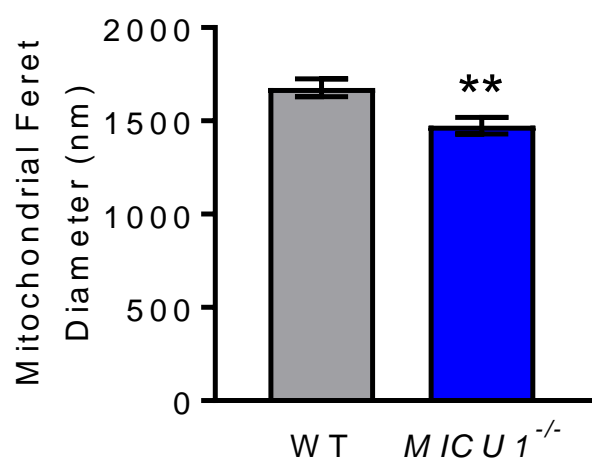

E

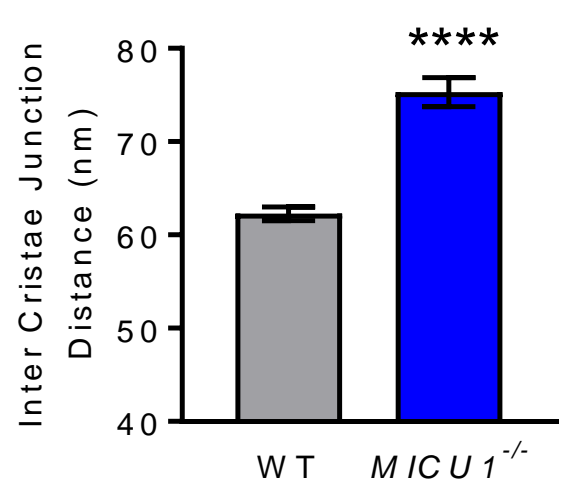

$\mathrm{H}$
G

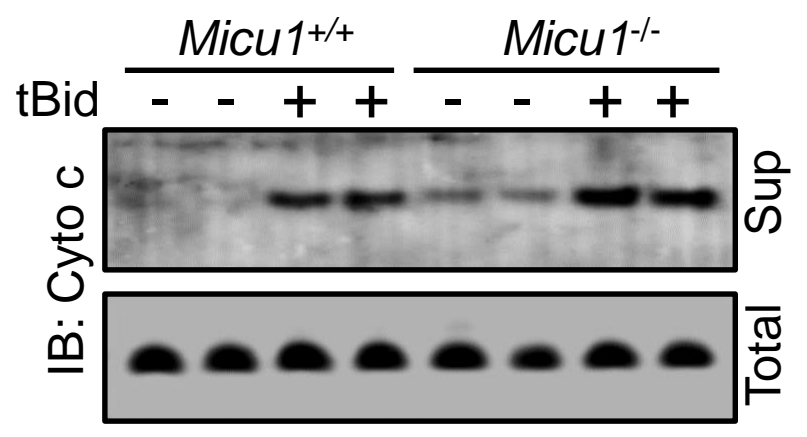

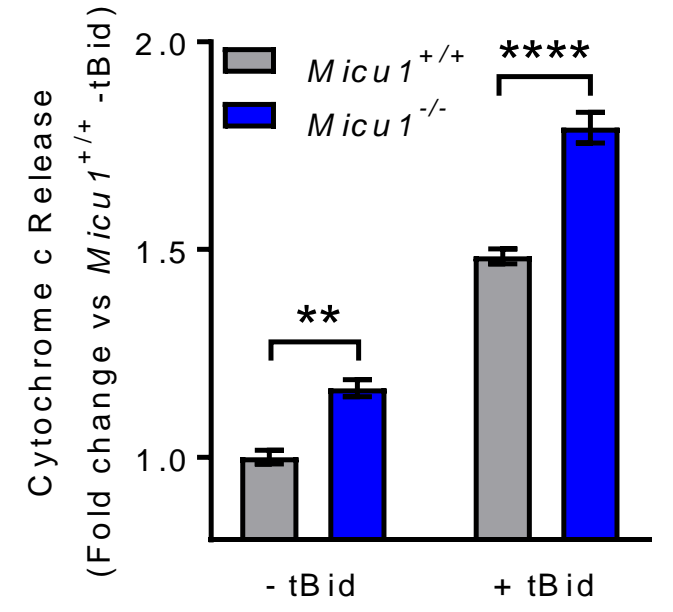




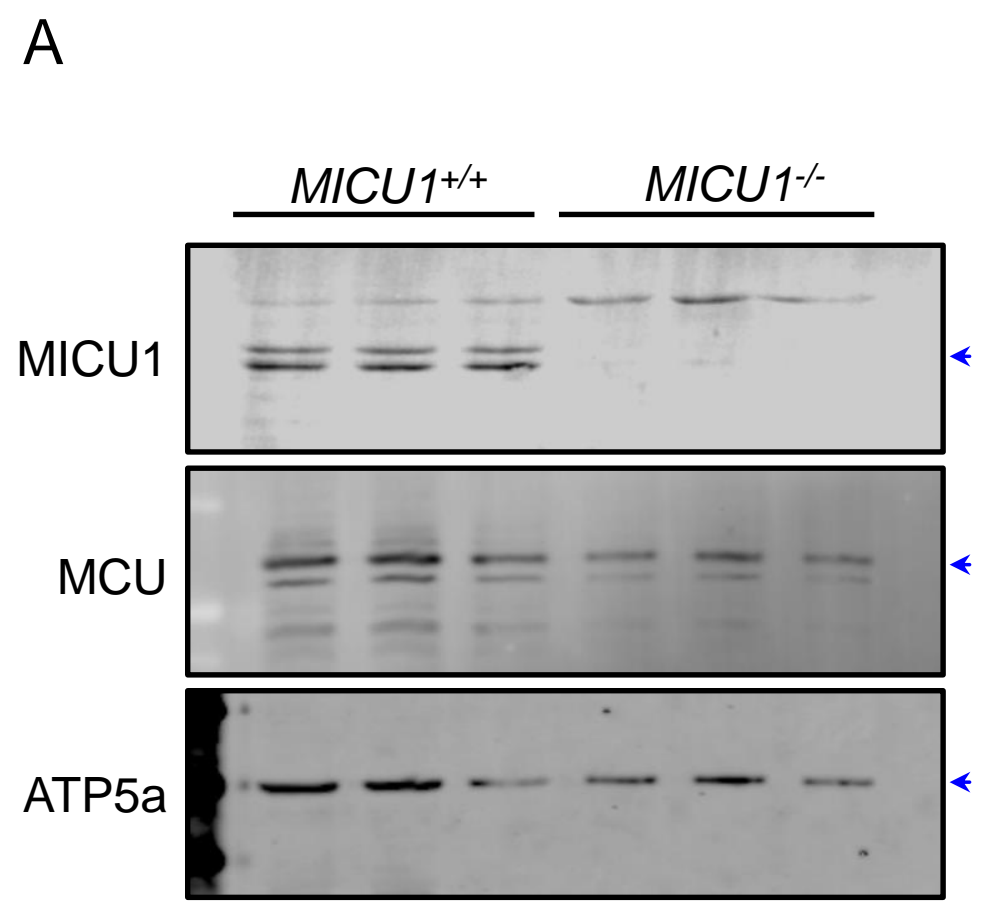
$\mathrm{B}-\mathrm{MICU} 1^{+/+}+\mathrm{BiolD} 2-\mathrm{HA}$
- $M I C U 1^{-1-}+$ BiolD 2-HA
- MICU1 $1^{-1}+\mathrm{MICU} 1$-BiolD 2-HA

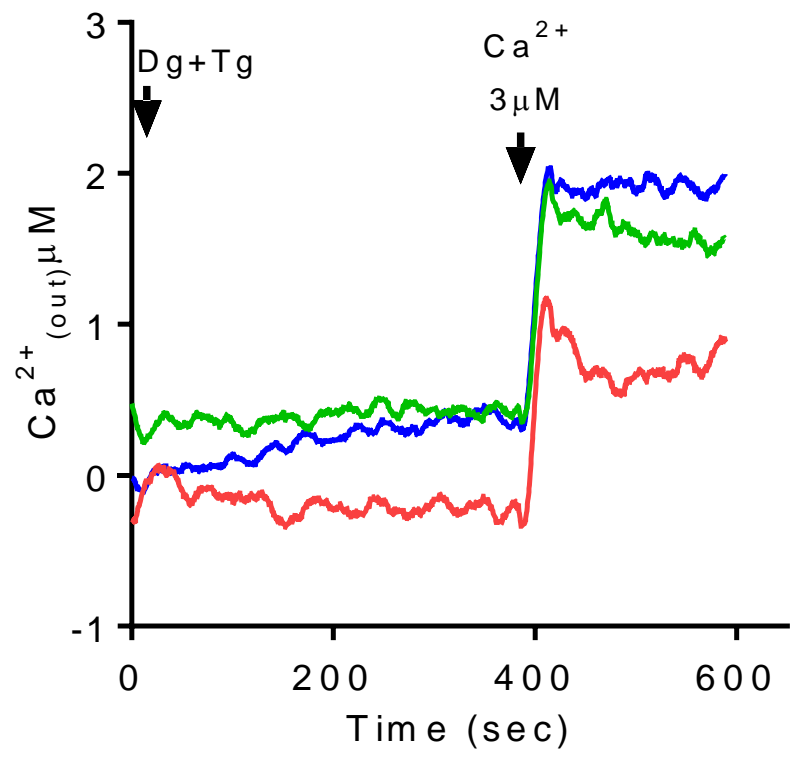


A

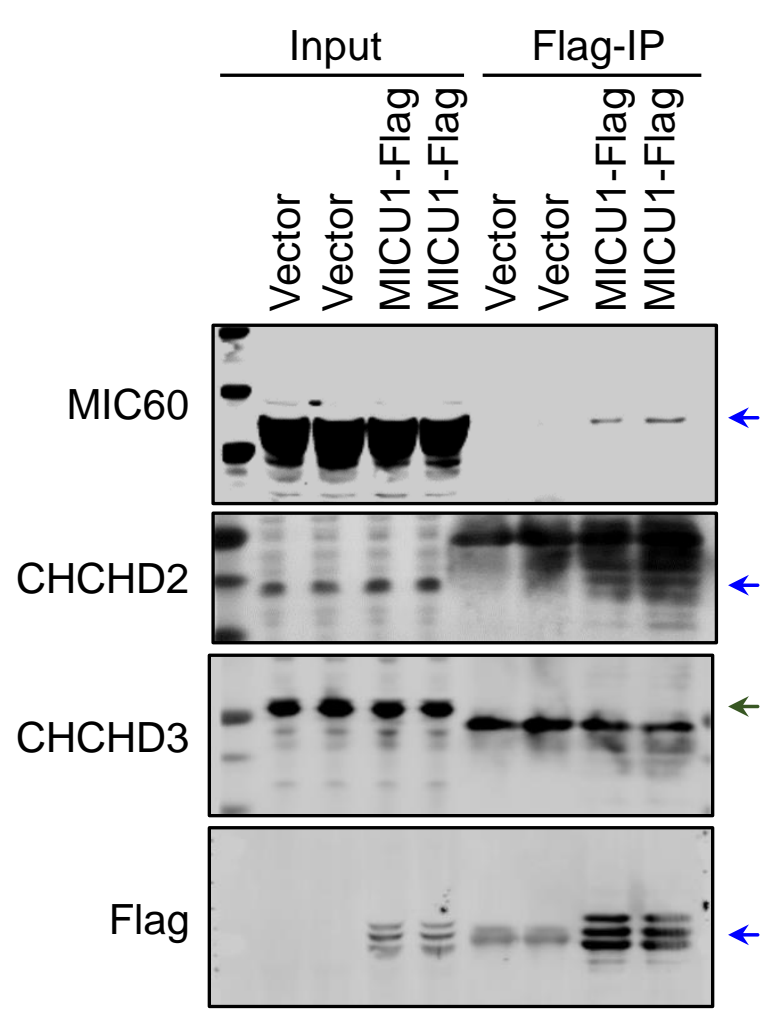

B

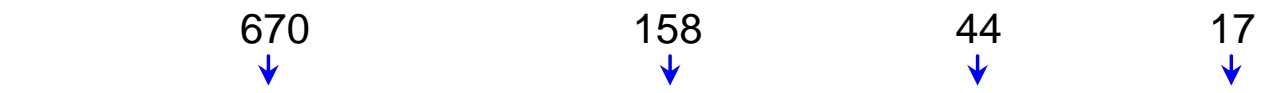

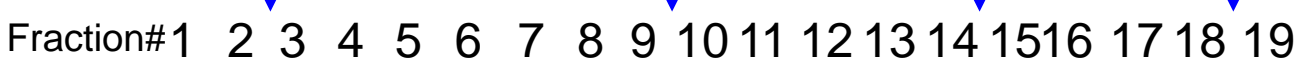

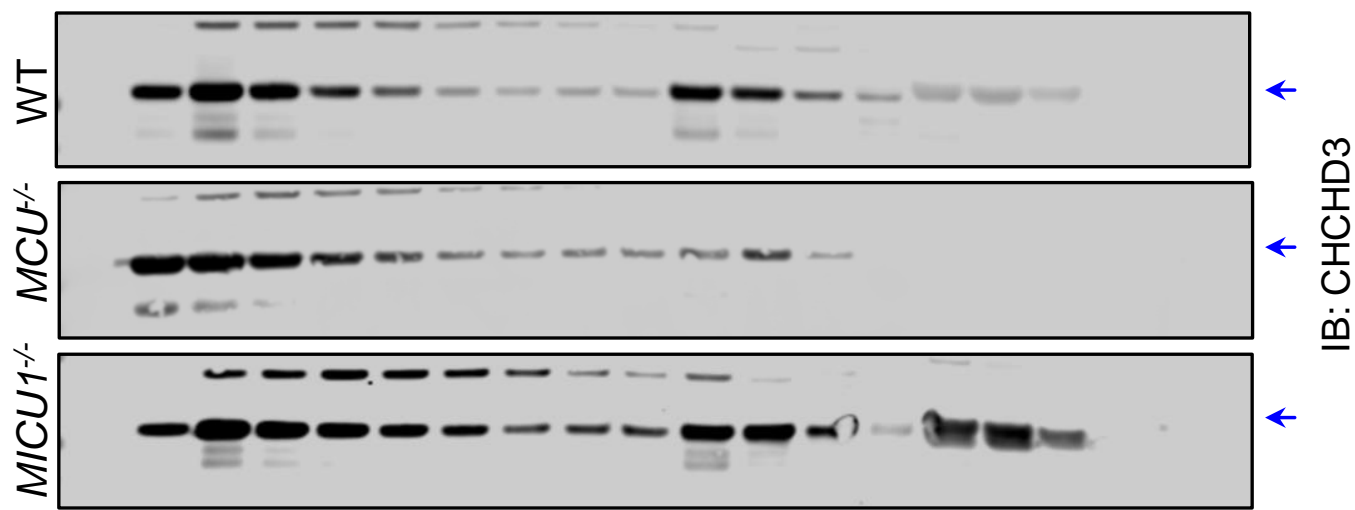

C

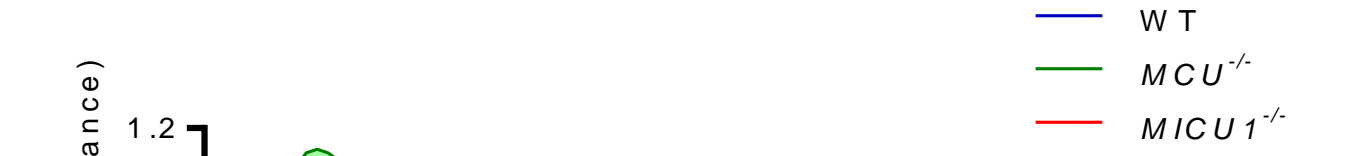




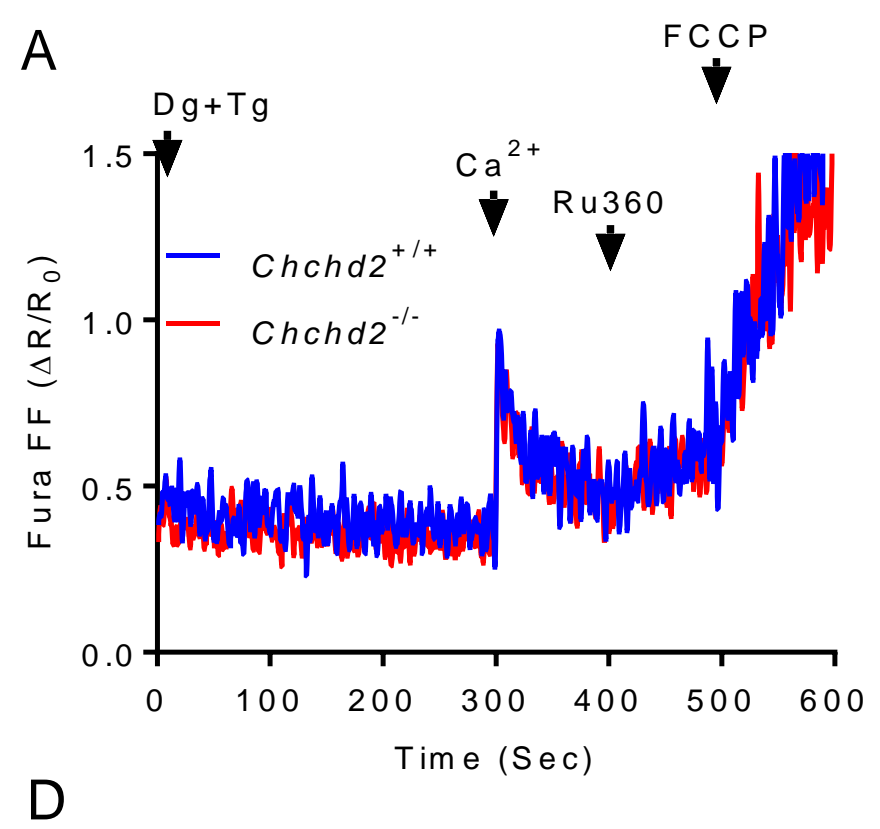

670
B

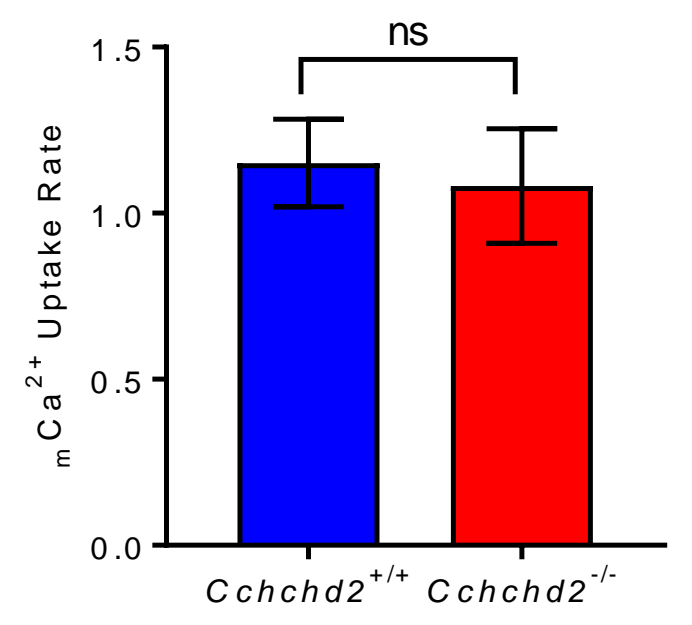

C

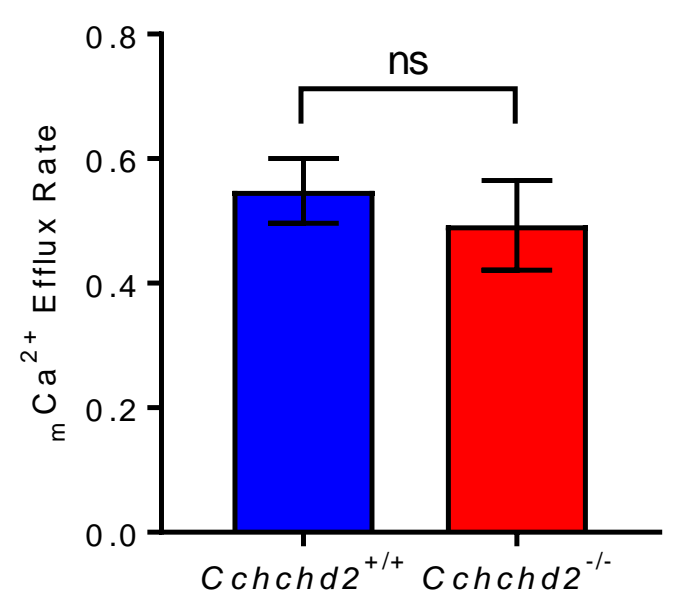

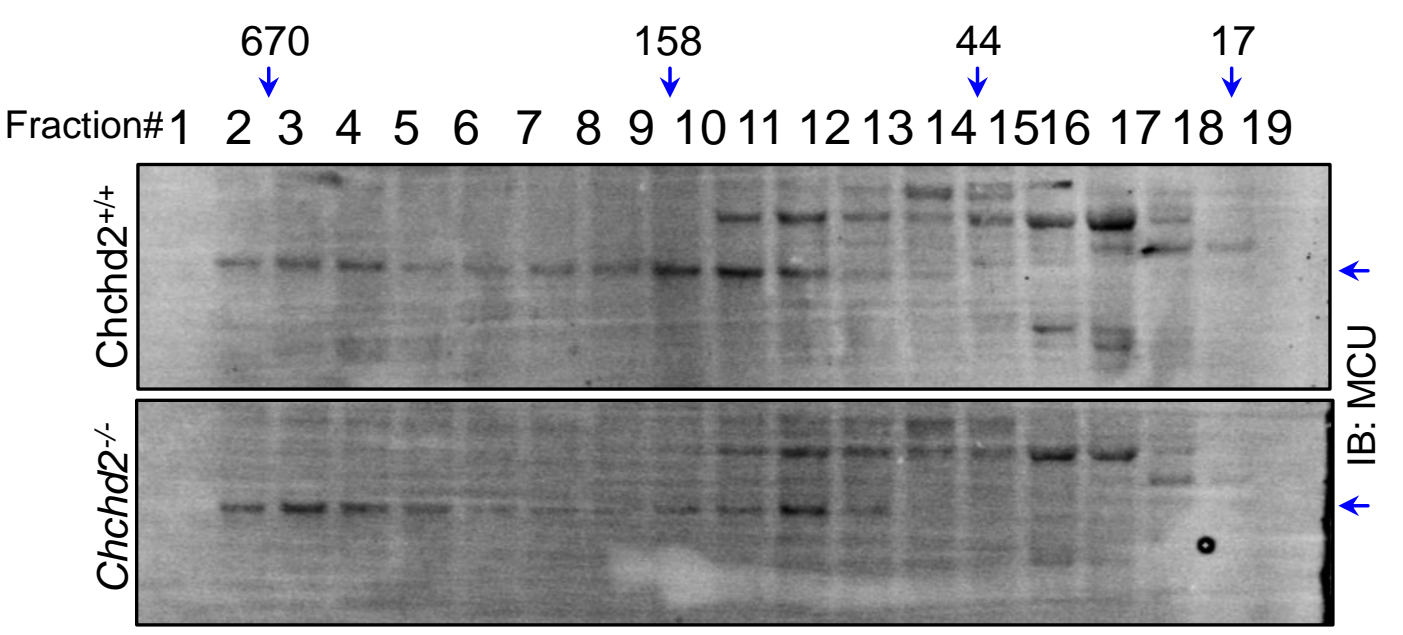

E

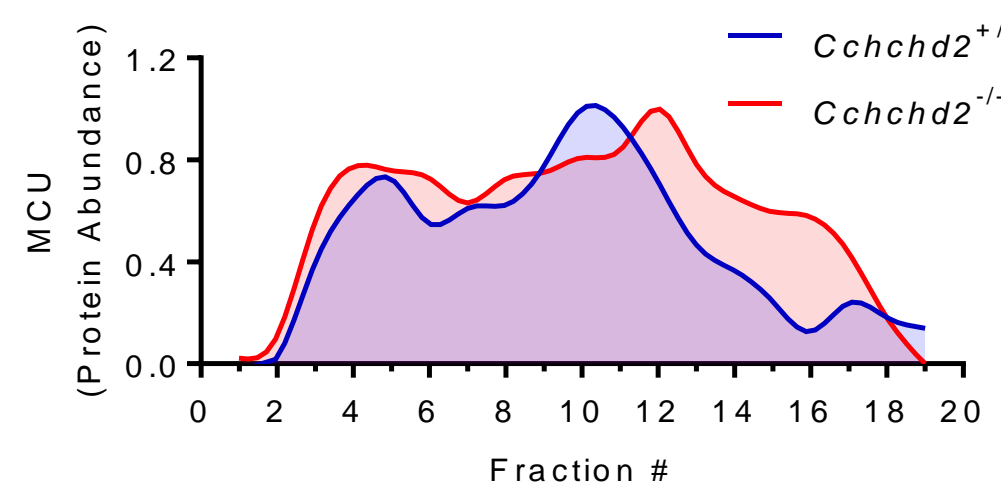

